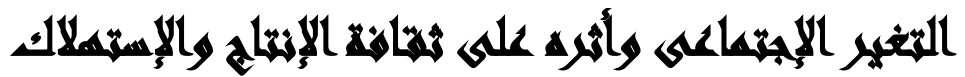

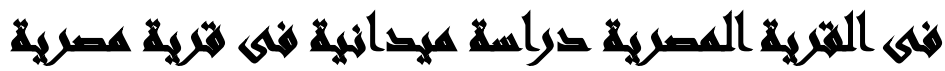

[?]

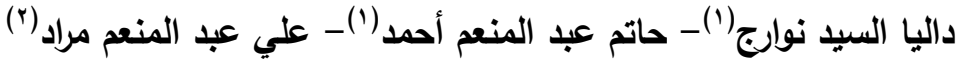

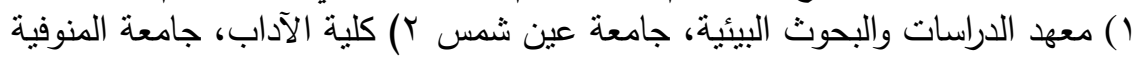

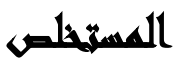

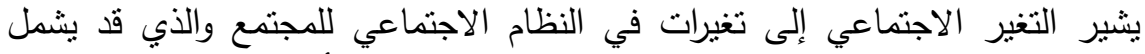

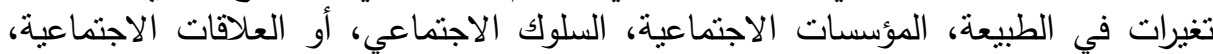

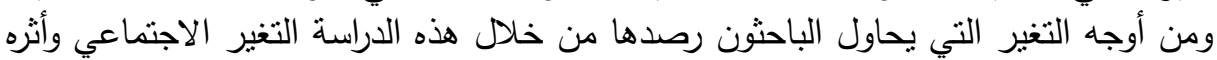

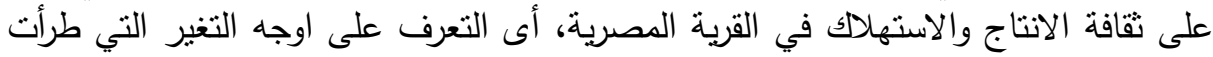

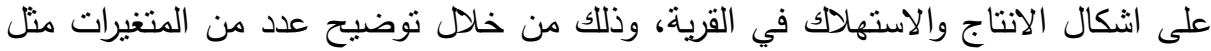

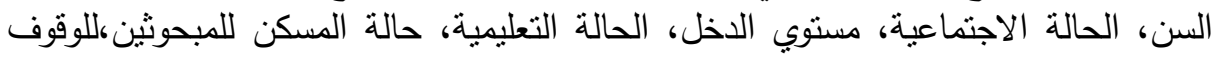

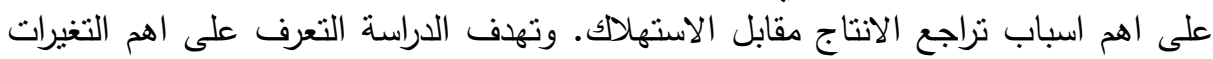

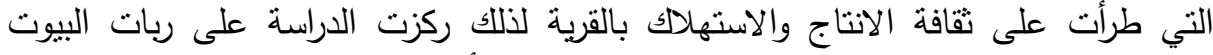

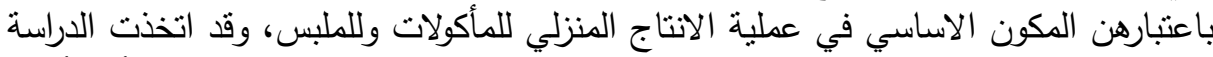

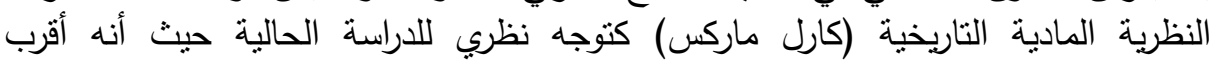

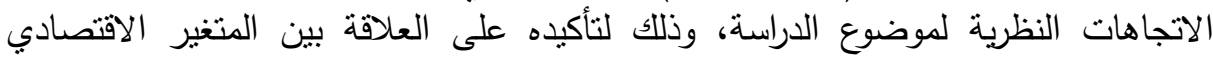

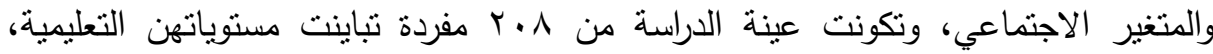

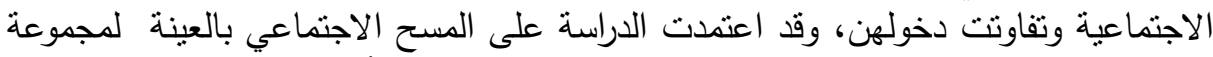

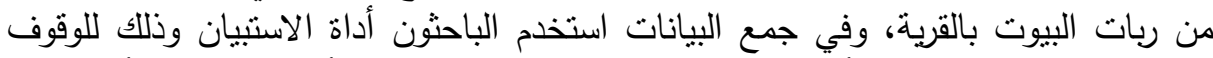

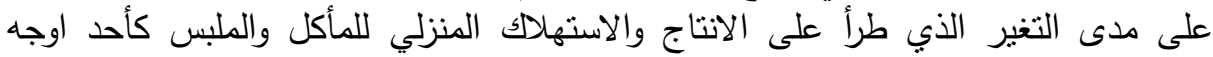

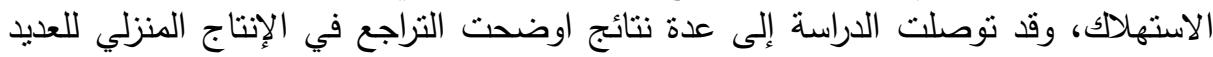

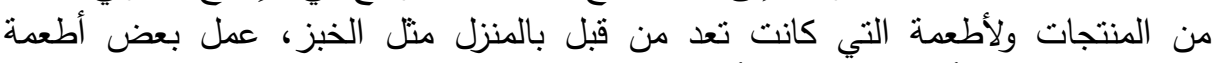

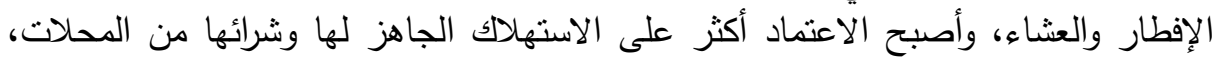

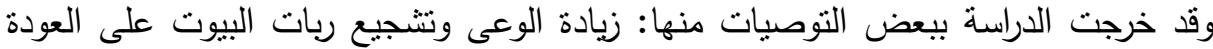

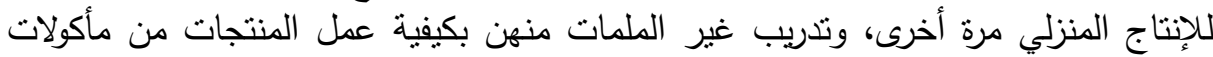
وملابس ومنسوجات بالإمكانات المتاحة، نرشيد الاستهلاك والحد من الهدر في الموارد. 


\section{anand}

يتقدم الزمن ويتغير وكذللك الحال مع عمر الانسان وحتى المجتمع يترافق مع هذه التغيرات، ولقد اهتم علماء الاجتماع والأنثروبولوجيا بدراسة أنواع التغير وصوره المختلفة، وشكل اهتمامهح به هدفاً أساسياً سواء في مجال العمل الميداني والنظري، فبالتغير يتهيأ للمجتمعات التكيف مع الوقائع المختلفة وبالتغير يتحقق التوازن والاستقرار في أبنيتها وأنشطتها وعن طريق التغير تواجه الجماعات متطلبات أفرادها وحاجاتهم المتجددة. (معن خليل

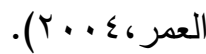

والتغير الاجتماعي قد يكون بطيئا وخاصة في المجتمعات البدائية ذات العلاقة الدحدودة

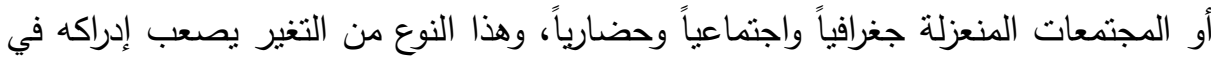
فترة قصيرة ويمكن أن يحدث أيضا بشكل تدريجي وهادئ لأن المجتمع الذى لا يتغير يكون

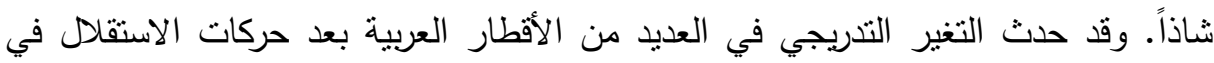

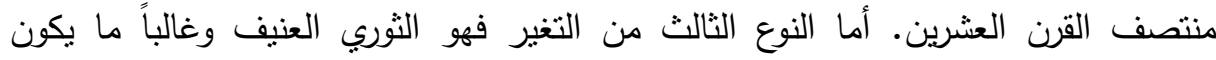
مصاحبا لثورة تعمل على إحداث تغييرات جذرية في الملكية والعادات والقيم والتقاليد والتعليم. ومن هذه الثثرات ثورة بr يوليو 190r في مصر والتي غيرت من توزيع الملكية وعملت

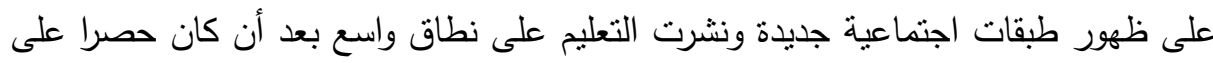

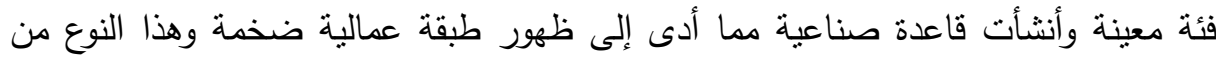
التغيير يكون سريعا ويمكن إدراكه بسهولة. وهناك الكثير من العوامل تتضافر معا وقد تحدث

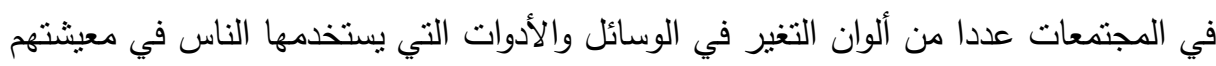

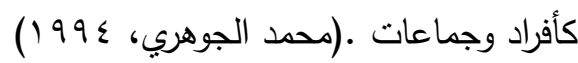
ولكن مع كل هذه التغيرات التي لحقت ببنية المجتمع الريفي ،كنتيجة طبيعية للتغيرات

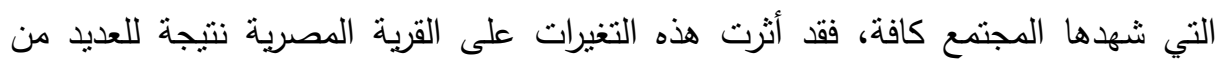
العوامل منها التغيرات السياسية والتي صاحبها تغيرات اجتماعية واقتصادية، كفترة الانفتاح

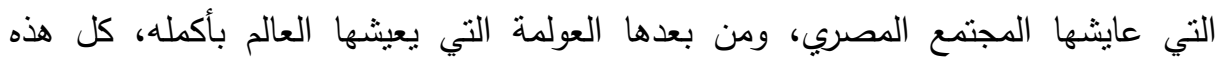


التغيرات أثرت على المجتمع الريفي وحدثت اختلافات هائلة في كل شئ فيه .(محد عبد النبي، (99) (199)

وتتتاول الدراسة الحالية ظاهرة هامة تتعرض لها غالبية القرى المصرية وهي ظاهرة التغير الاجتماعي وتغير أثكال الاستهلاك بها وتراجع الإنتاج، فلقد ساعد التقدم التكنولوجي لناهي بوسائله المختلفة على حدوث تغير في العادات الاجتماعية والقيم لدى غالبية القرى المصرية وتبدل حال القرية من مجتمع مغلق يقاوم التغير الى مجتمع منفتح يقبل التغير ويستسيغه.

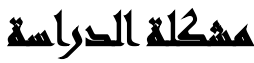

تتاولت العديد من الدراسات مثل دراسة(محد ياسر الخواجة، .... ب)، والتي بعنوان

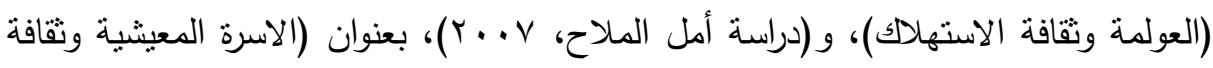

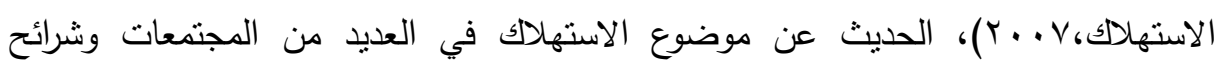

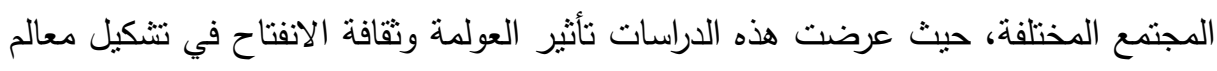

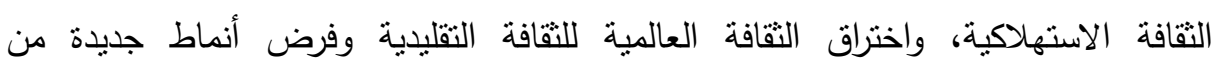

$$
\text { الاستهلاك، وزيادة الطبقي، وزيادة معانة الثعب المصري. }
$$

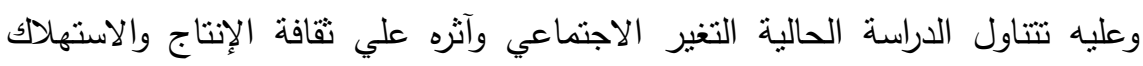

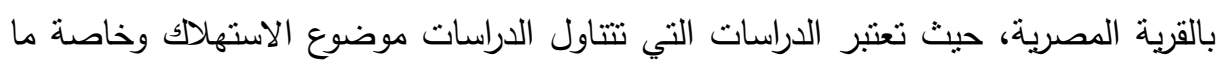

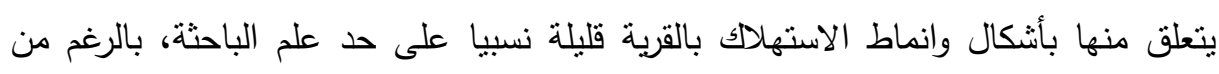

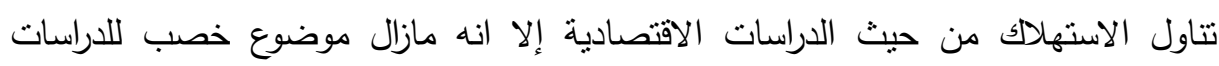

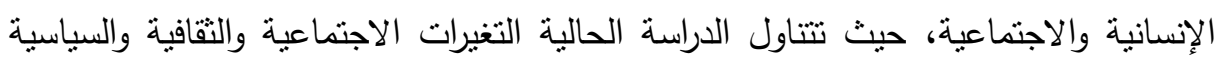
التي أثرت على كافة الأنساق الاجتماعية نجد ان المجتمع القروي لم يكن بمعزل عن هذه التهاته التغيرات.

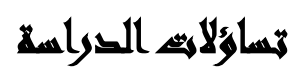

تنتاول الدراسة تساؤلين رئيسيين هما: 1- ما أهم التغيرات الاجتماعية التي طرأت على ثقافة الإنتاج والاستهلاك في القرية؟

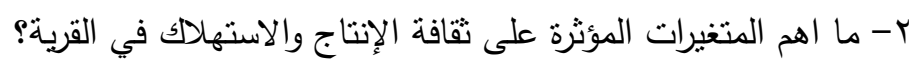




\section{أهمه التوراسة}

تتضح أهمية الدراسة الراهنة في أنها نعمل على زيادة النراث النظري في موضوع هام يشغل بال الكثير من الدارسين، والمهتمين بموضوع التغير والمهتمين بالدراسات المتعلقة بالريف بشكل خاص، فعلى المستوى المعرفي يعمل الموضوع على إثراء التراث النظري بني

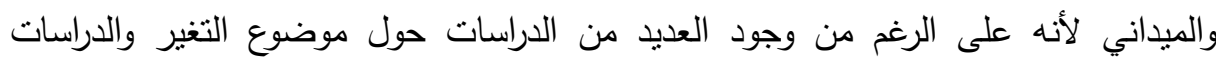
المتعلقة بالقرية المصرية إلا أنه تتدر الدراسات المتعلقة بدراسة بعض القيم المبن المستحدثة والناتجة

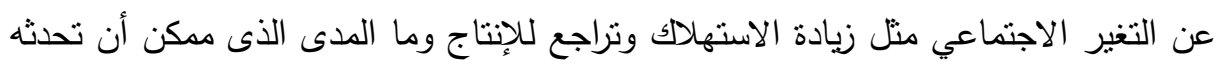
وجود منل هذه القيم في الريف المصري.

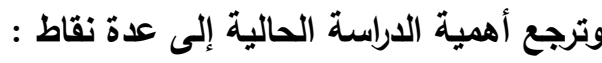

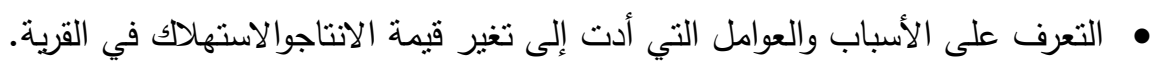

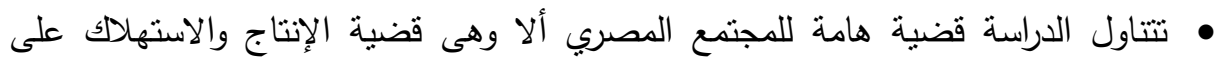
اعتبار أنه أحد المجتمعات النامية والذى يتأثز بأى تغير يحدث فيه هيه.

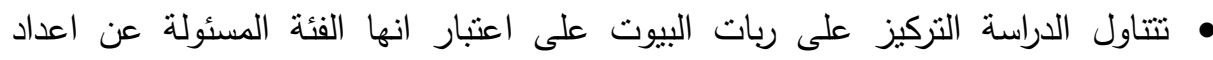

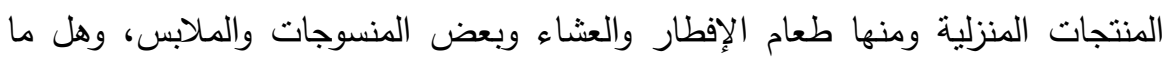

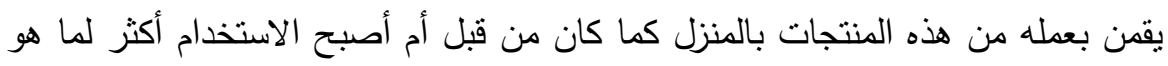

$$
\text { منتج خارج المنزل. }
$$

\section{أهسا هـ القواسما}

• التعرف على التغير الاجتماعي وأثثر على ثقافة الإنتاج والاستهلاك في القرية. • التعرف على أهم المتغيرات المؤثرة على ثقافة الإنتاج والاستهلاعك في القربية.

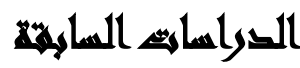

تعد الدراسات والأبحاث السابقة مصدراً مهماً لأبحاث أخرى فيطلع الباحث على المجلات

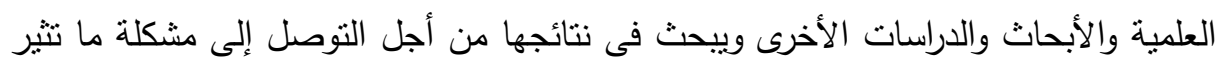


الإهتمام، كا يساعد استعراض الدراسات أيضاً فى التخطيط لمشكلة البحث بحيث يغطى جميع

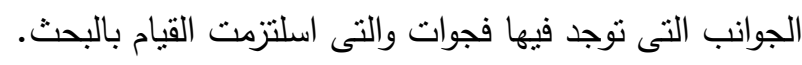

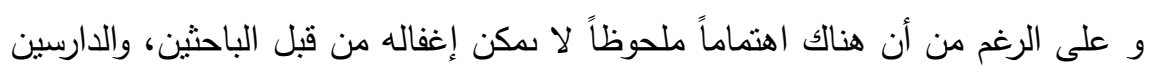

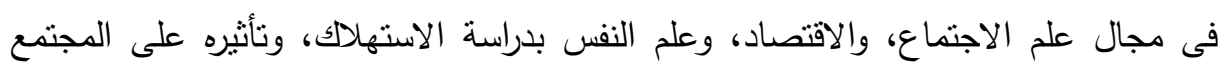

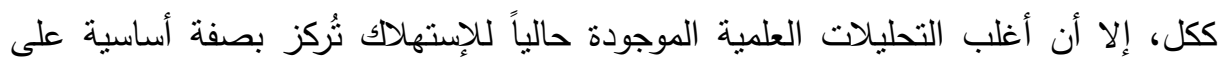

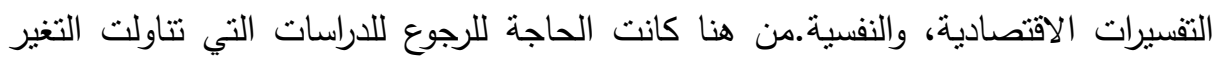

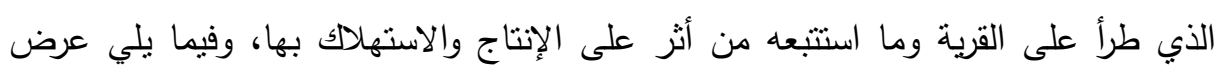

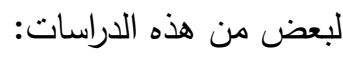

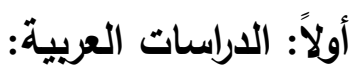

- دراسة (هبة يوسف عثمان ) 11 بـ هدفت هذه الدراسة إلى: الكثف عن التغيرات فى بعض العادات الإجتماعية والقيم البيئية التى طرأت على القيفئ القرية المصرية

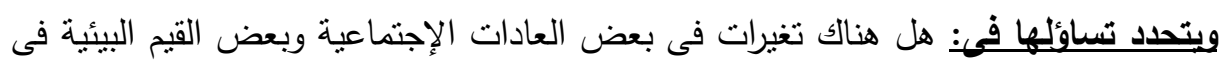
قرية ببلاو؟ واعتمدت الدراسة على: المنهج الوصفى في وصف وتحليل مدى التغير في العادات بالقرية،

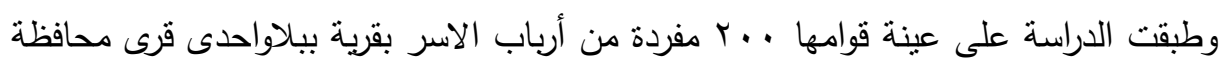
اسيوط.

واستخدمت الباحثة أداة الاستبيان ودليل المقابلة المتعمقة كأدوات للدراسة، وجاعت

\section{النتائج التي توصلت إليها الدراسة:}

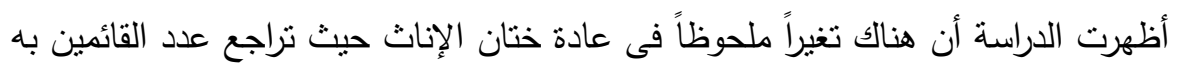

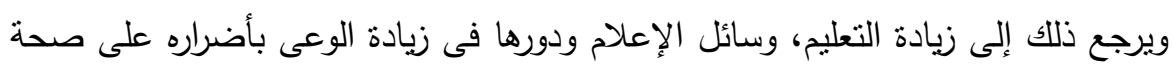

تراجع عدد زيجات الأقارب وأصبح من حق الفتاة والفتى اختيار شريك الحياة، زيادة التعليم

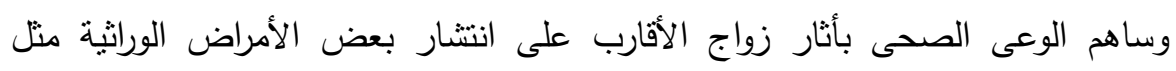


بالنسبة لعادة الأخذ بالثأر فقد كثفت الدراسة عن أن غالبية الأفراد أصبحوا يوافقون على الصلح، لعدة اسباب منها منع كثرة الدماء، وأيضاً أصبح الثباب يفكروا فى مسنقبلهم وذلك الكانك

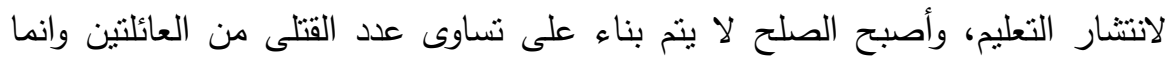
بتقديم الكفن لعائلة القتيل. • بالنسبة للمحافظة على الهواء من التلوث كثفت الدراسة عن زيادة نلوث الهواء عن الماضى ويرجع ذلك إلى الاهمال، وأن غالبية أفراد عينة الدراسة يتخلصوا من المخلفات

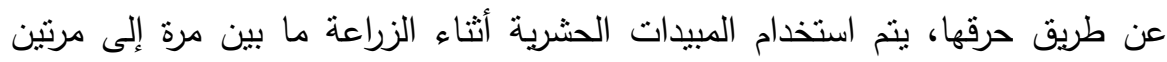
أسبوعياً.

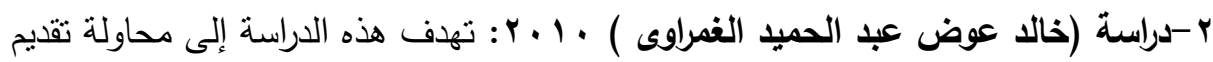
فهم سوسيولوجى لكل من العوامل التى تدفع المصريين لإقتتاء أجهزة استقبال البث المباشر

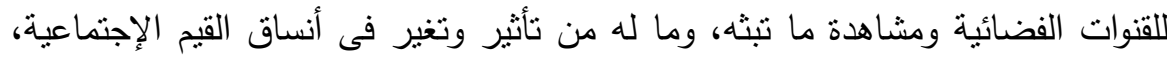

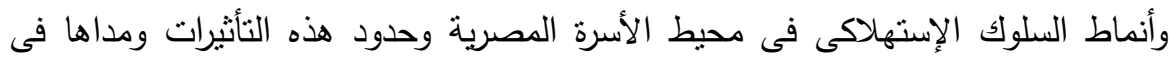

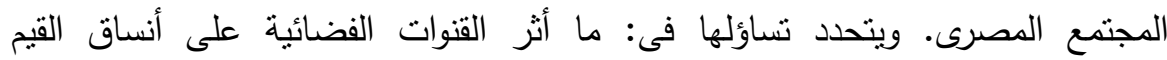
الإجتماعية وأنماط السلوك الإستهلاكى فى المجتمع المصرى؟ استعان الباحث بالمنهج الوصفى لوصف تغير انساق القيم للاسرة في المجتمع المصري في ظل منابعة محتوى ما تبثه القنوات الفضائية، واستخدم الباحث فى هذه الدراسة دليل مقابلة متعقة يتناسب مع تساؤلات الدراسة. وبالنسبة لعينة الدراسة فقد نم اختيار عينة عرضية بالصدفة من منطقتى مصر الجديدة

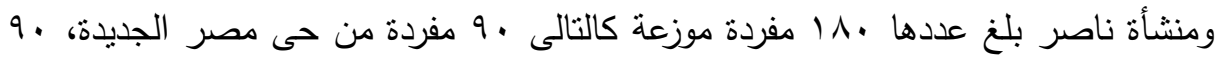

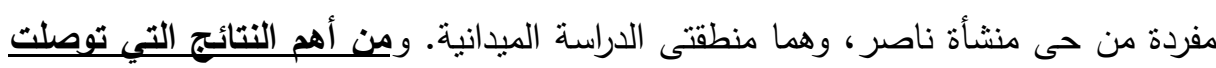

• أوضحت النتائج اهتمام الجمهور المصرى بمتابعة القنوات الفضائية المصرية والعربية أكثر من القنوات الفضائية الأجنبية وذلك لسهولة استيعاب المادة الإعلامية العربية العربية عن المادة الإعلامية الأجنبية بسبب اللغة والثقافة، وصعوبة استيعاب المادة الإعلامية 
الأجنبية بسبب اللغة فضلاً عن اختلاف الموضوعات والقضايا التى تتتاولها البرامج والمواد الإعلامية العربية عن المواد الإعلامية الأجنبي، وتركز الإهتمام فى منابعة الإنهات

$$
\text { المسلسلات والأفلام والأغانى والبرامج الحوارية. }
$$

أوضحت نتائج الدراسة أن القنوات الفضائية لا تترك آثارها على الفرد فقط بل بلى يمند ناثيرها إلى قنوات التليفزيون المحلى، فقد ذكر أكثر من نصف العينة أن استقبال القنوات الفضائية يتزك آثنار سلبية على القنوات المحلية. تمنلت فى عقد المقارنات الظالمة بين قنوات التليفزيون المحلى والقنوات الفضائية الأخرى.

تباينت آراء عينة الدراسة حيث أوضحت النسبة الغالبة من العينة أن سلبيات القنوات الفضائية تفوق ايجابياتها، وأن أضرارها أكثر من فوائدها.

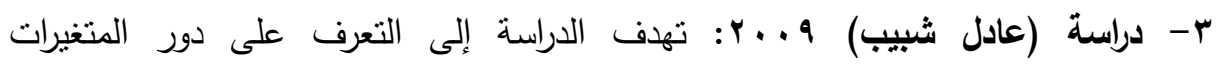

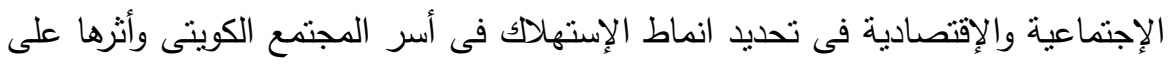
مدى تحقيق التوافق الاجتماعي لدى هذه الأسر.

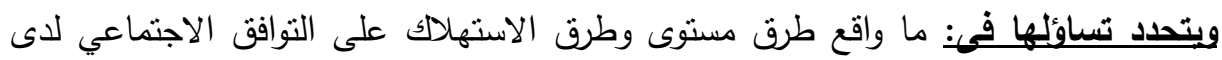
الأسر مع تعدد البيئات المنتمية إليها؟ واستعان الباحث المنهج الوصفى، بالنسبة للأدوات المستخدمة للدراسة، تم استخدام كل من: الملاحظة بالمشاركة، استمارة الاستبيان، الخرائط الطبوغرافية، الصور والأرقام الحكومية، وقد قام الباحث باختيار عينة عشوائية متعددة المراحل تتكون من .س مفردة، من سكان مدينة الفنطاس التابعة لمركز محافظة الأحمدى التابعة لدولة الكويت.

\section{أهم النتائج التىى توصلت إليها الاراسة:}

• ترجع زيادة الإستهلاك بشكل أساسى إلى ارتفاع متوسط دخول الأسر إضافة إلى أن

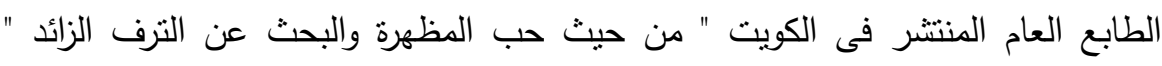

• توجد علاقة طردية بين ارتقاع متوسط الاخل وزيادة الإستهلالك.

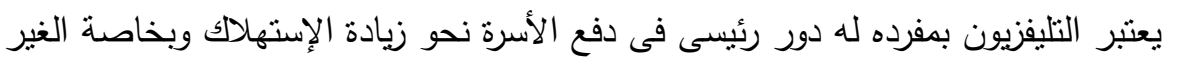
رشيد. 
• لاحظ الباحث ان الحاجة للشئ قد لا تكون الدافع لثرائه بقدر ما يكون الإبها بطريقة

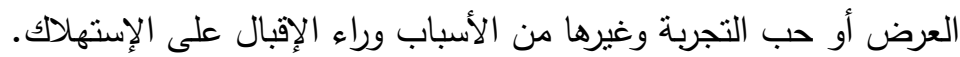

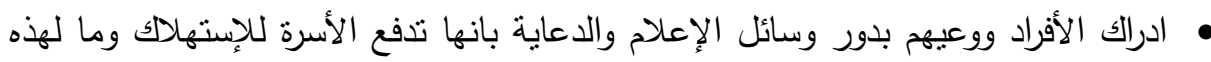

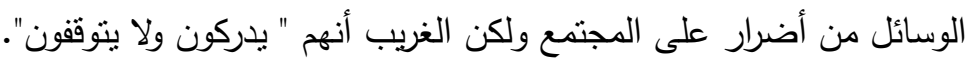

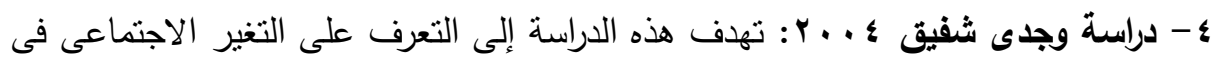

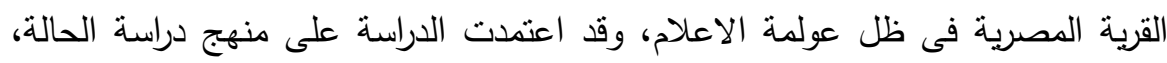
والمسح الاجتماعى، وتم جمع البيانات من خلال أداة الملاحظة بالمشاركة، واستمارة

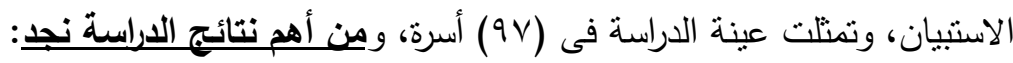

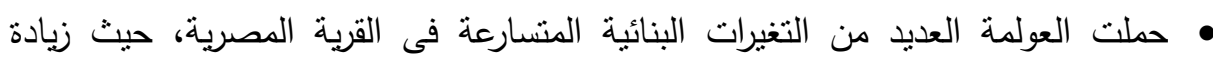
الطابع الاستهلاكى، وإقبال الكثير من الأسر على شراء السلع الكمالية.

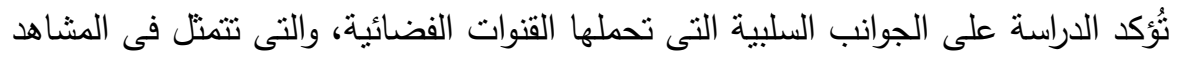

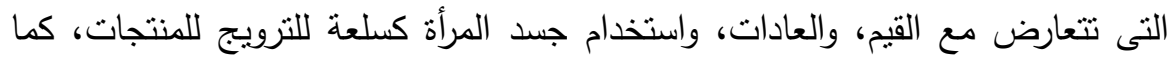
تغير نمط الملبس لدى فئة الثباب من الجنسين.

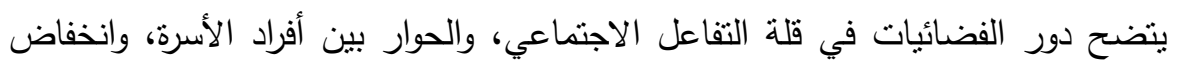
نسبة الزيارات الأسرية.

\section{ثانيا الدراسات الأجنبية ومنها:} ا-دراسة 2011. Xina, Y , et al : تهدف هذه الدراسة إلى التعرف على العوامل التى تحدد ظهور القيم الاستهلاكية، وذلك فى اطار الاختلافات الثقافية بين دول شرق آسيا،

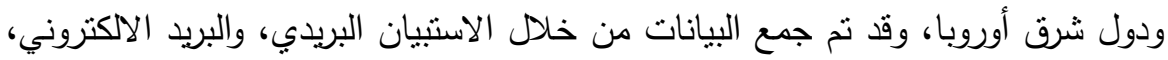

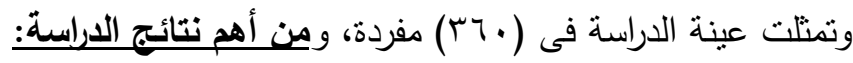
• تتمنل العوامل التى تحدد ظهور القيم الاستهلاكية فى: سلوك المستهلك، والحاجات الثرائية، والقيمة الوظيفية للمنتج، ومدى الرغبة فى تحقيق النفوذ من خلال عملية الاستهلاك، والقيم الاجتماعية، والثقافية. 
• أوضحت الدراسة الاختلافات الثقافية بين المستهلكين، حيث تفوق المستهلكون فى دول شرق آسيا على دول أوروبا الثرقية فى الانتماء للتقافة الوطنية، والتمسك بالقيم الاجتماعية، والحفاظ على التماسك الاجتماعي. هيتخح من خلال الاتجاهات الشرائية للمستهلكين فى دول أوروبا الثرقية غلبة الثية قيم النزعة

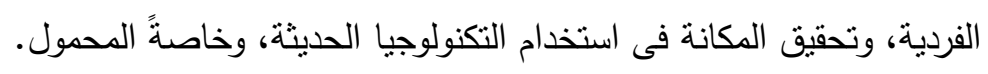
ץ-دراسة 2009 . Abdul Razak Kamaruddin , et al : تهدف هذه الدراسة إلى التعرف إلى التعرف على عملية اتخاذ القرارات الثرائية لاى المستهلكين فى ماليزيا، وذلك

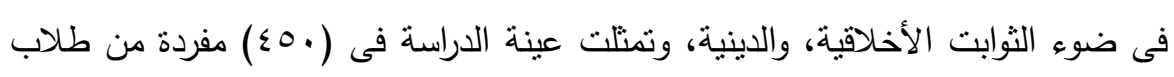

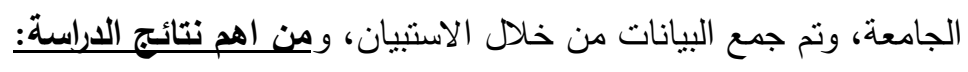

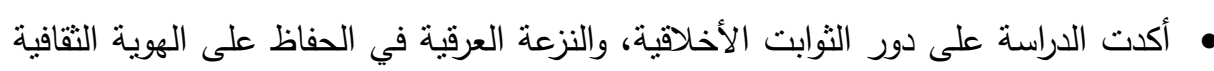
لاى المستهلكين، وذلك لأنها تتبع القيم الدينية الاسلامية.

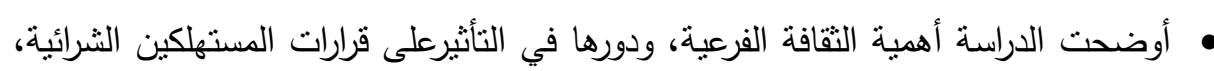
حيث يرغب المستهلكون في الحصول على المنتجات عالية الجودة، ولكن في حدود الامكانات المادية المتاحة، وهنا نظهر الصعوبة في التوفيق بين القيم الدينية، والأخلاقية، وبين الخبرة التسويقية للسلع، والمنتجات.

\section{هناهيه الدواسم}

مفهوم التغير الإجتماعى: يشير مصطلح التغير الإجتماعى إلى" التحولات أو التبدلات فى بناء المجتمع أى فى الهياكل الأساسية فيه، منل حجم المجتمع وتركيب أجزائه المختلفة

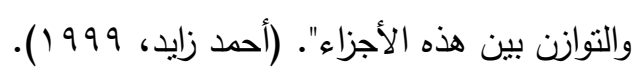

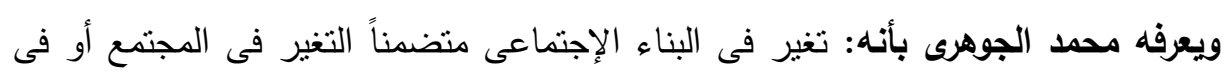

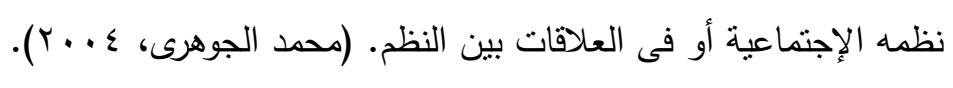

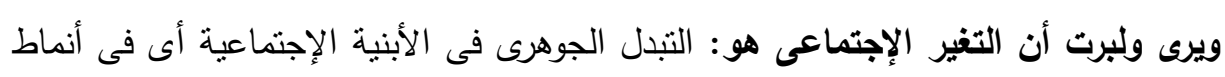

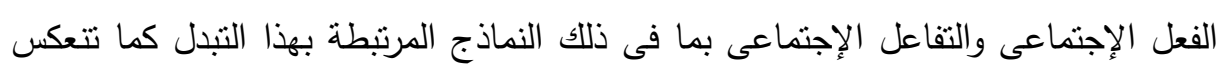


فى التغيرات التى نطرأ على القيم والمعايير والمعتقدات الثقافية والرموز سواء ركزت على

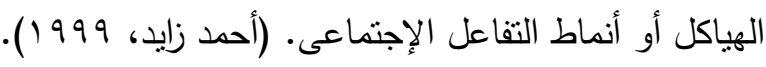
تعريف "Bogradus" للتغير الإجتماعى: حيث يقول أنه كل تحول يقع فى مجنمع من الإنمان المجتمعات خلال فترة زمنية محددة ويصيب الأنساق والنظم والظواهر والتنظيمات الإجنماعية سواء كان ذلك فى البناء أو الوظيفة، كما يشتمل أيضاً على التغير فى السلوك والأفكار والمعتقدات، ويحدث التغير الإجتماعى نتيجة تفاعل العديد من المتغيرات وليست نتيجة متغير واحد، ويتخذ التغير الإجتماعى صور وأثكال مختلفة منها التطور الإجتماعى والحراك

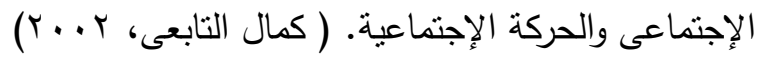

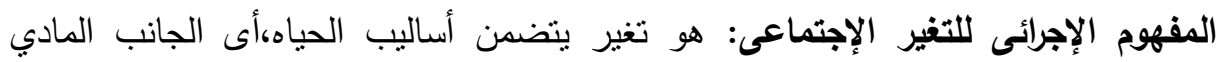
واللامادي معا والجانب المادي يتمنل في انثاء (المصانع، البنية البنية التحنية، المؤسسات) واللامادي للتقافة ويشمل ( العادات والتقاليد والقيم) كاستجابة لعمليات التتمية. مفهوم الإنتاج: هو نتاج العناصر أو القوى التي تستخدم (المدخلات) في عمليات التشغيل، والتي تتمثل ببساطة في كل من القوى البشرية (العمال) والمادية (رأس المال المستثر في عناصر الأصول الثابتة والمتداولة المختلفة) خلال فترة زمنية معينة. (سوزان أحمد

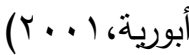
المفهوم الاجرائي للإنتاج: هو استخدام الموارد المتاحة في الحصول على سلع وذلك باستخدام الأيدي العاملة ورأس المال وفي تحويل هذه الموارد إلى أو تحويلها من موارد عديمة القيمة إلى في سلع ومنتجات ذات قيمة تستخدم لإثباع حاجات لدى الأفراد. مفهوم الاستهلاك: يعرف الاستهلاك في المعجم الوجيز يقال استهلك: أى جهد نفسه فيه

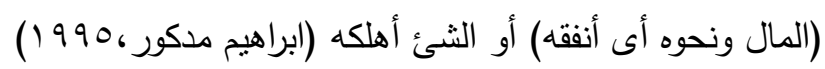
ويعرف الاستهلاك بأنه "النشاط الذي يثبع به الإنسان حاجاته ويتوقف الاستهلاك على الدخل

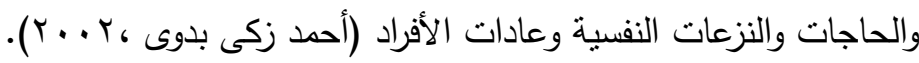


مفهوم ثقافة الاستهلاك:يمكن تعريف نقافة الاستهلاك على أنها " ثلك الجوانب الثقافية المصاحبة للعملية الاستهلاكية، فهى مجموع المعاني والرموز والصور التي تصاحب التهبن العملية

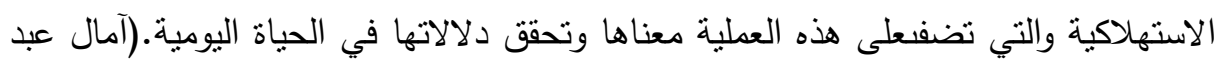

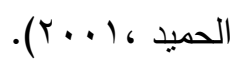

ولا ترتبط ثقافة الاستهلاك بالجوانب المادية المرتبطة بالممارسات الاستهلاكية، ولكنها

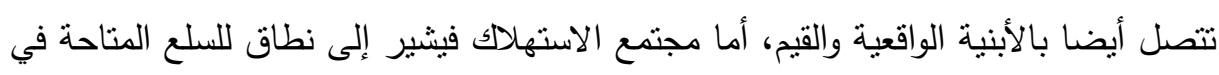

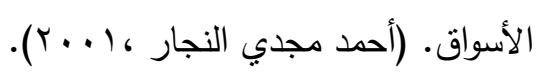

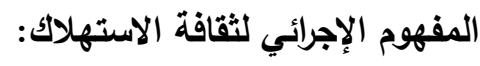
• هو النشاط الذي يحتاج إليه الإنسان ليشبع احتياجاته. • ترتبط هذه الاحتباجات بالدخل الذي يحصل عليه الفرد وعاداته الاستهلاكية لتلكئك الحاجات. • ويرتبط نمط الاستهلاك بمدى توافر تللك السلع والحاجات التي يحتاج إليها الفرد لإثباع احتياجاته.

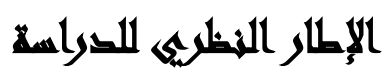

تمهيد: تعد النظرية الموجه الرئيسي للاراسة حيث تستمد الدراسة قوتها من النظرية ومعطياتها والافتراضات التي تعتمد عليها، وقد رأت الدراسة إن التعدد والتنوعفي الموجهات النظرية ضروري لفهم طبيعة مجتمع الدراسة وما يموج به من متغيرات اجتماعية وثقافية والوقوف على طبيعة التغير من حيث الاسباب والعوامل والمقومات. K. أولاً: النظرية المادية التاريخية (كارل ماركس): لقد استخدم كارل ماركسية Mzarx المادية وتحلل طبيعة مظاهر الحياة الأساسية ولاسيما قضية الإنتاج الاقتصادي الذى يعتبر

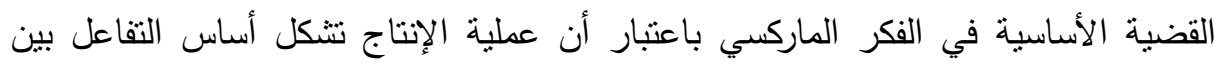
جوانب الحياة الاجتماعية. 
و ترى الماركسية أن أى مجتمع مهما كانت طبيعة المرحلة التاريخية التي يمر بها من

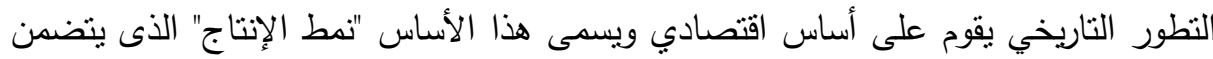

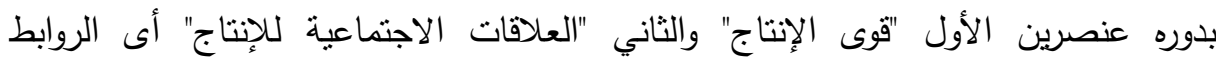
والعلاقات التي لا مفر منها والتي يجب أن يدخل فيها البشر مع بعضهم البعض ألثاء وراء قيامهم

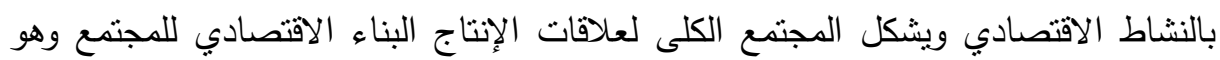
الأساس الحقيقي الذى يقوم عليه البناء الفوقي للدجمع.( عدلي أبو طاحون ، 999 ( ) )

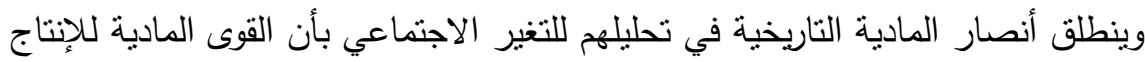

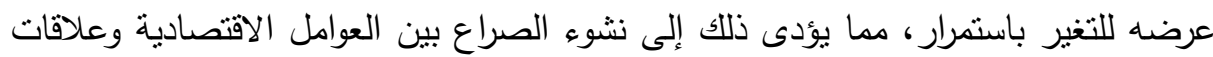

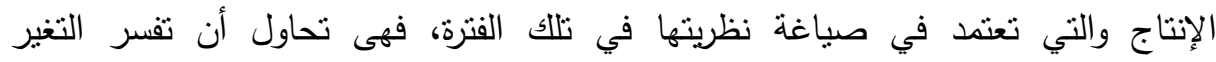
الاجتماعي البنائي عن طريق فهم العلاقات التي يدخل فيها الناس من أجل انتاج واستخدام

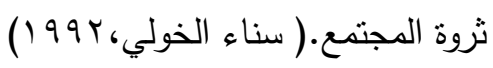

كما أوضح ماركس أن القوى المسئولة عن التغير كامنة في المجتمع ذاته وليست راجعة

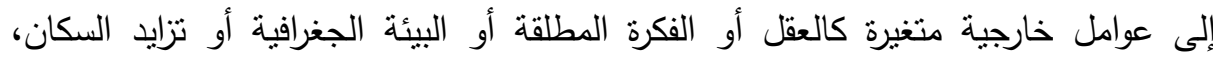

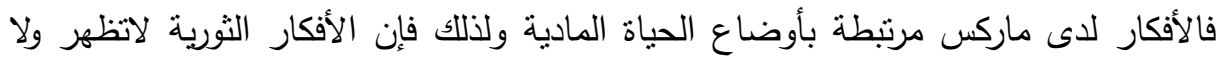

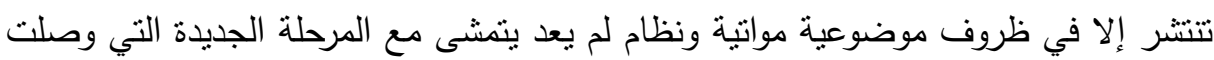

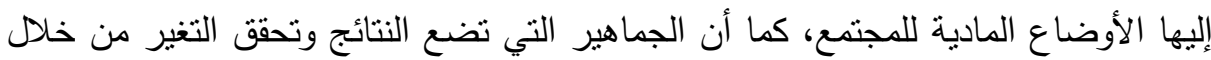

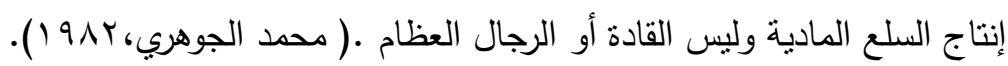

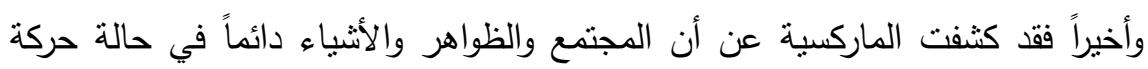
وتطور وتغير وأن هذا النطور أى الجانب الدينامي للمجتمع هام، وتجاهله يؤدى إلى فهم

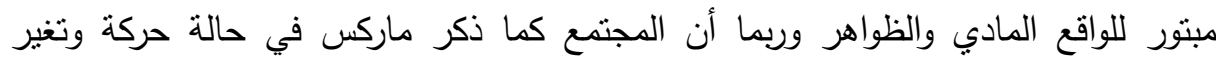
وتطور والأسرةهى جزء من المجتم، فإن أى تغير يصيب المجتمع ينرك آثاره وانعكاساته

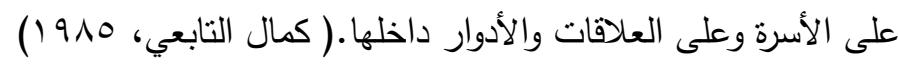
والواضح أن ماركس قد حاول تحليل وتقسير التغير الاجتماعي عندما ذهب بأن العملية تتطلب باستمرار تحولاً في العلاقات الاقتصادية، وهذا التحول كثثراً ما يؤدى لعدة تغيرات 
اجتماعية تؤثر في البناء الاجتماعي والطبقي فيالمتمع، فقد أعتمد ماركس في تحليله للتغير

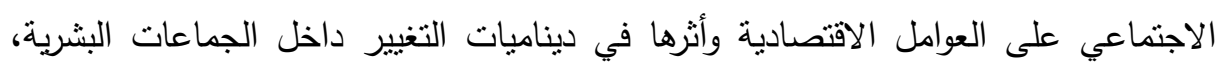
وبهذا نجده ركز على تأثز العلاقات الإنسانية بالنواحي الاقتصادية.

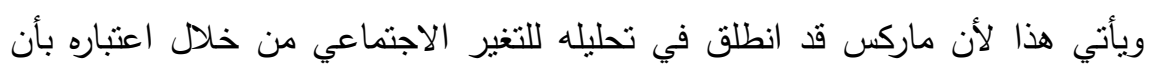
الاساس الاقتصادي للمجتمع بمثابة قوى حقيقية للتغير الاجتماعي لأنه يحدد المستوى العام

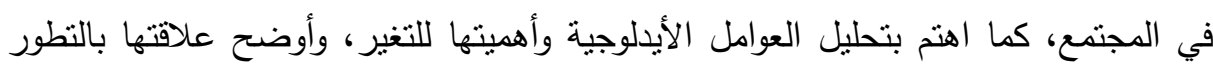
التكنولوجي الذى وجده لبعض التغيرات في شكل الانتاج والنظم والعلاقات التي تحكم النسق والنق الاقتصادي في المجتم، وأثرها على النظام الأسرى نتيجة دخول المرأة ميدان العمل والنتائج

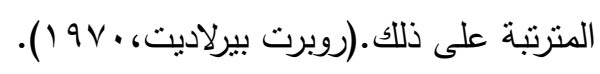

ومن خلال نظرة سريعة لنظرية ماركس في التغير الاجتماعي نستطيع أن نستخلص النقاط

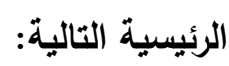
• أن النطور والتغير الاجتماعي يقوم على أساس العلاقات ونمط الانتاج الذي يشكل بدوره النظم الاقتصادية. • العامل الاقتصادي هو العامل الأساسي في بناء المجتمع.

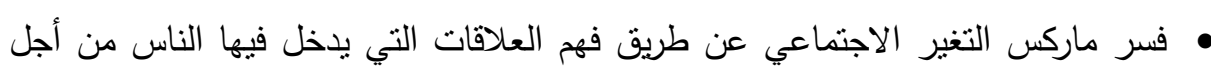

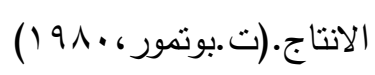

الماركسية المحدثة: وقد قدم " ألتوسير " تصوراً محدداً للعلاقة بين مفهومى البناء التحتي

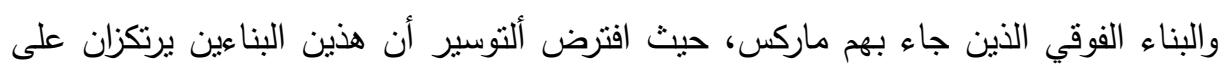
مبدأين "الاستغلال النسبي للبناءات الفوقية" وما يترتب عليها من نتائج محددة، والتأثنر الحتمي لأني

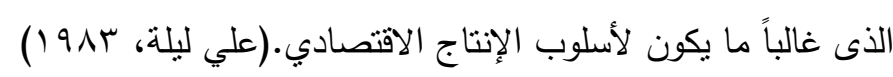

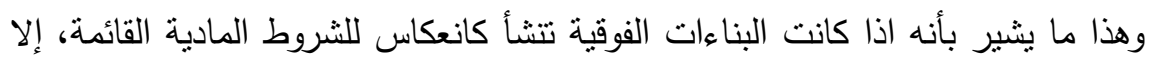
أن قدرتها على الاستمرار تكون بدرجة أكثر من الثروط المادية. والواضح أن الماركسية

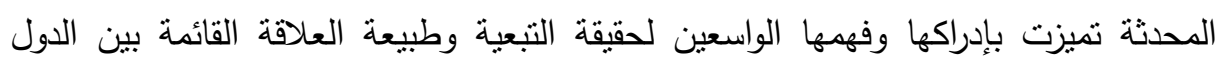
المتقدمة والدول المتخلفة، لذا فقد أكدت الماركسية المحدثة على دراسة العالم كوحدة متكاملة وذللك على الرغم من أن معالجة ماركس للرأسمالية اقتصرت على المستوى العالمي وذلك

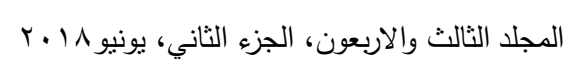


باعتبار أن الرأسمالية ليست عملية متجانسة ونمط متجانس وانما هى: " علاقة متكافئة بين

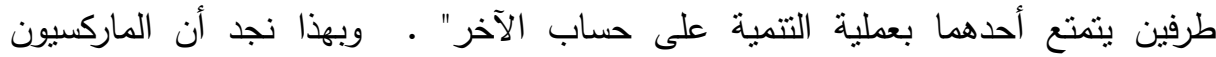

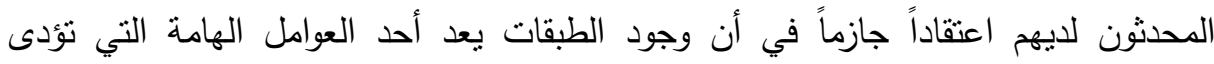

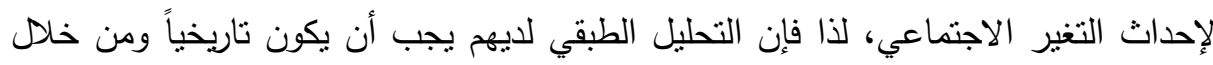

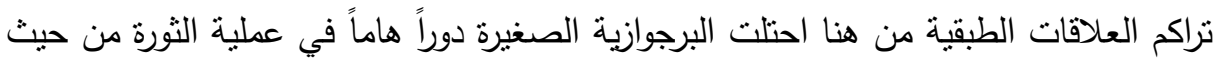

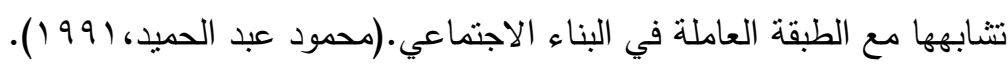
وعلى الرغم من الانتقادات التي وجهت للنظرية الماركسية، إلا أن أهم ما يميزها أنها كانت نظرية سوسيولوجية حاولت تفسير التغير الاجتماعي في ضوء عمليات داخلية في

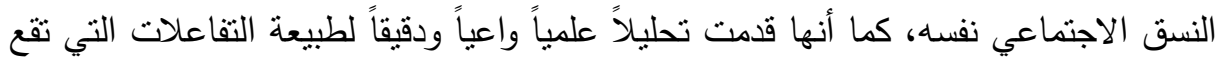
في إطار هذا النظام، هذا إلى جانب تقديم نظرية فعالة للتغير الاجتماعي القريب والبعيد

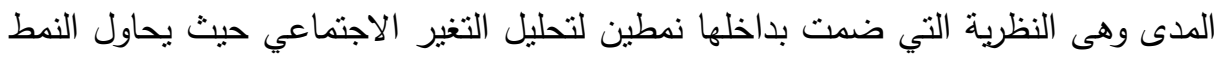

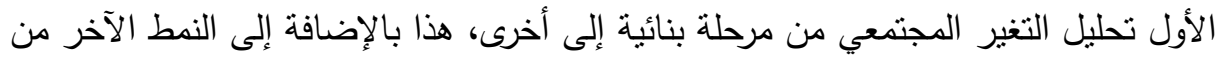

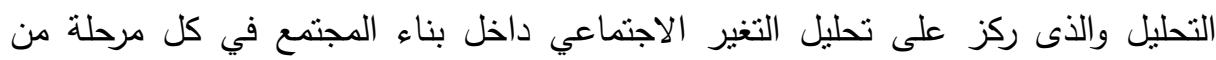

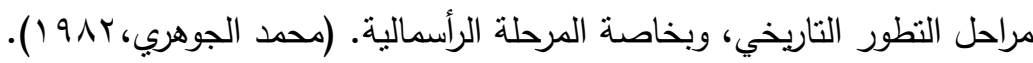

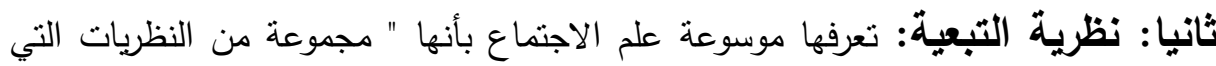
ترى أن فثل دول العالم الثالث في تحقيق مستويات ملائمة ومتواصلة من التتمية إنما برجع إلى تبعيتها للدول الرأسمالية المتقدمة، وقد تطورت نظريات التبعية لمواجهة المزاعم المتفائلة

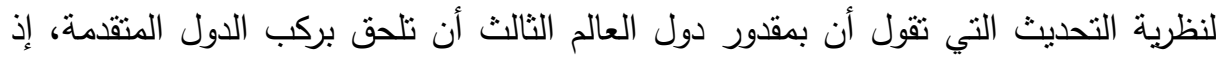

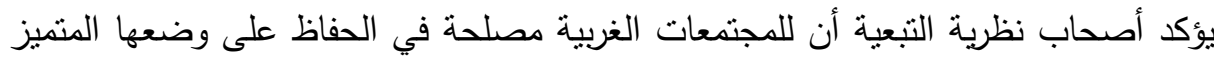
بالنسبة للدول النامية، وأن لديها الإمكانيات المالية والتكنولوجية لتحقيق ذلك لـوله (جوردون

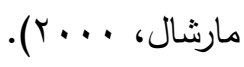

وقد كان " منظرو النمو الاقتصادي والتحديث أنصاراً متحمسين لطريق النطور الرأسمالي، وأعادوا بشكل ممض تكرار آراء الارتقائيين الين أدعوا أو ألمحوا إلى أن الرأسمالية

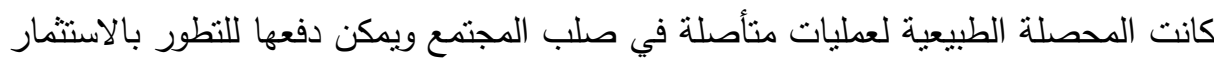


إما في القاعدة الاقتصادية أو في الدجموعات التي يستفيد أفرادها مادياً من تطورها، وزعموا

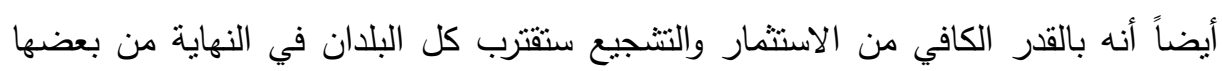

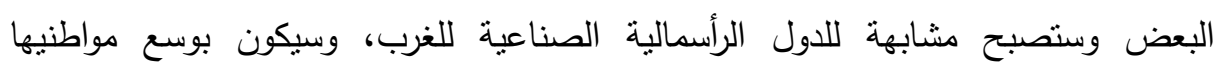

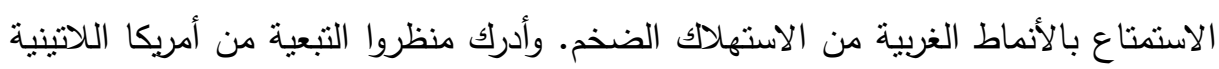

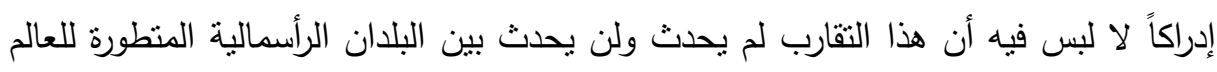

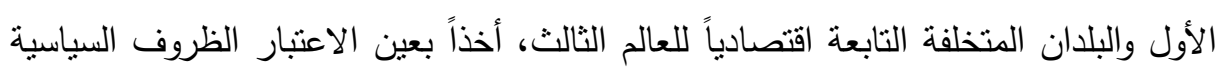
- الاقتصادية التي تبلورت بسرعة في الأعوام الثالية للحرب العالية الثانية الثانية (توماس س.

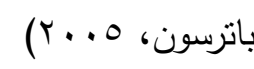

وهكذا فقد دفعتالأوضاع الاقتصادية المتدهورة في أمريكا اللاتينية في خمسينيات

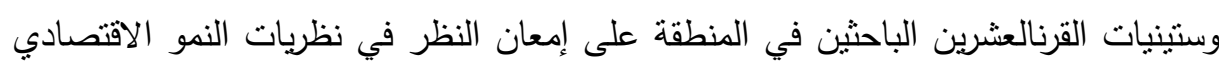

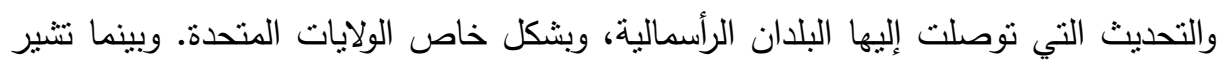

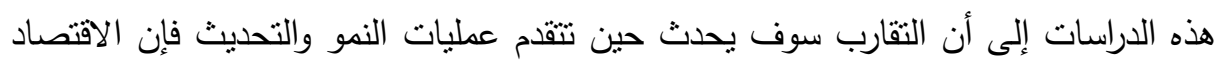

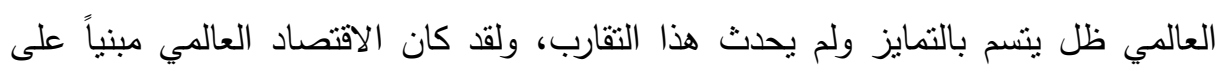

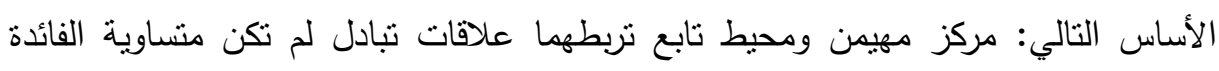

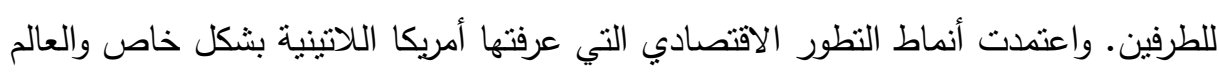

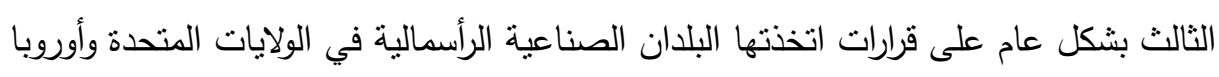

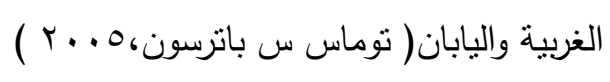

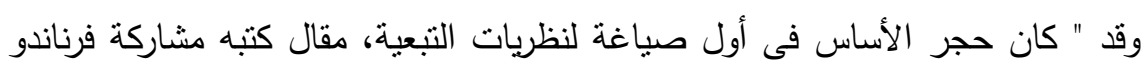

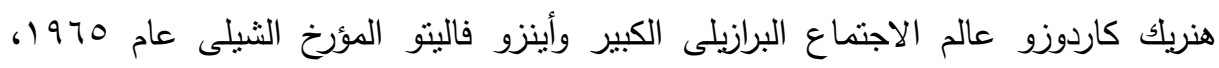

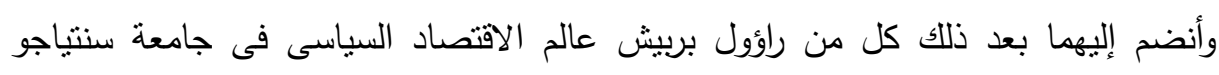

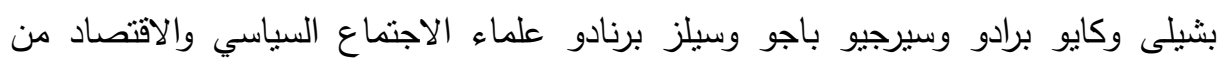

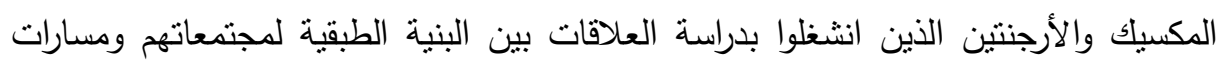

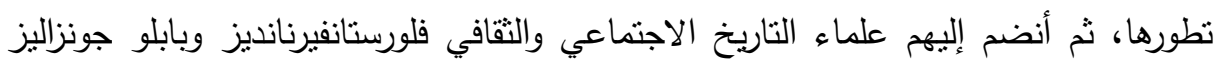

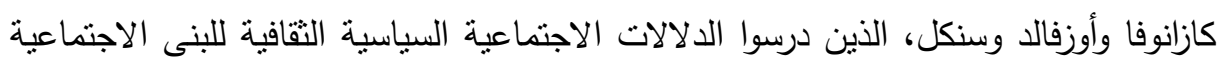

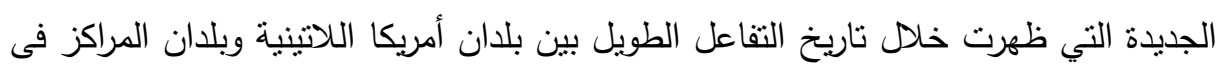

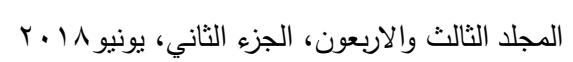


أوروبا والولايات المتحدة. وكان العالمان الكبيران كاردوزو وفاليتو هما من تمكنا من تجميع الدلالة النظرية المستخلصة من كل هذه الدراسات وصاغا منهجهما الذى أطلق عليه (المنهج

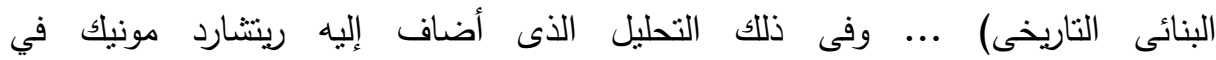

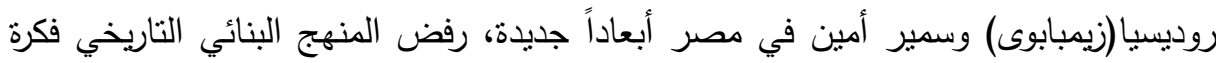

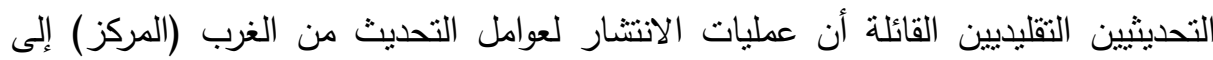
العالم الثالث هى التي دفعت إلى التحديث هناك،، لكن المنهج نفسه لم ينكر أن نفوذ المركز

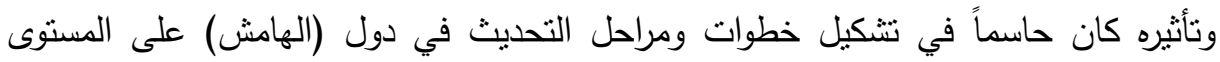

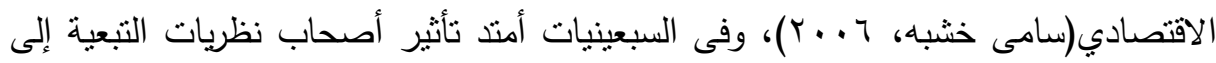

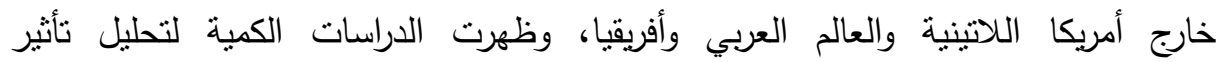

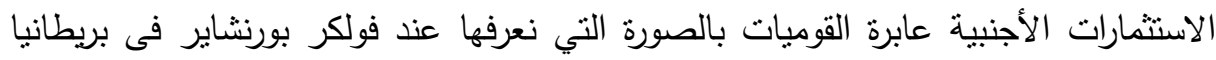

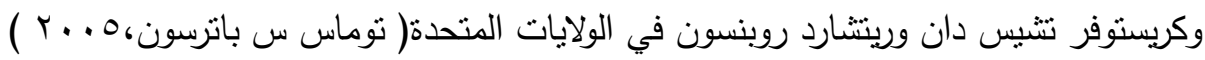

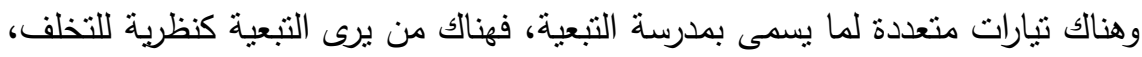
وهناك من يؤكد على محور استراتيجية المركز الرأسمالي، بالإضافة إلى رؤية أنباع النظام

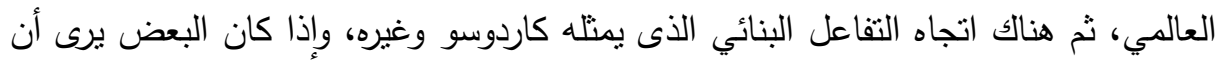

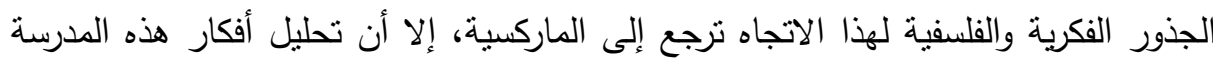

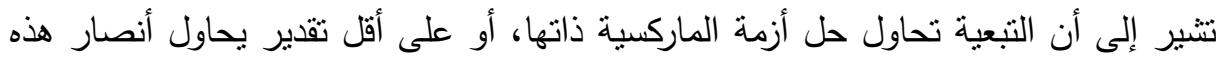

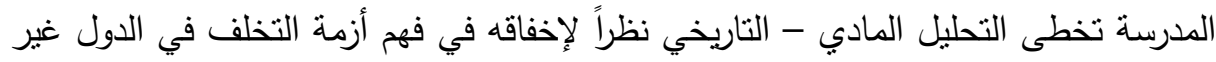
الرأسمالية أو في دول العالم الثالث (أحمد مجدى حجازي، بو 99 ( ). ويمكن إيجاز أهم افتراضات نظرية التبعية في النقاط التالية: - يؤكد أتباع نظرية التبعية أن التخلف والتقام وجهان لعملة واحدة، بدأت مع نشأة النظام الرأسمالي. ويقول فرانك في ذلك أن التخلف لم يكن حالة متأصلة في اقتصاديات دول

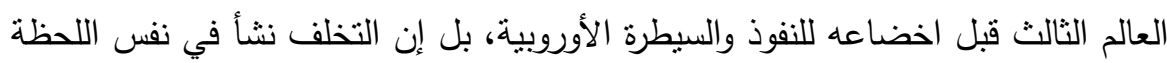

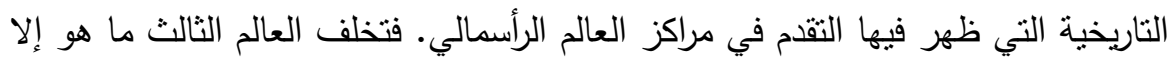
نتاج مباشر للتتمية في المركز الرأسمالي. 
- يؤكد أنصار التبعية على استنزاف فائض الدول المتخلفة وتصديره إلى المراكز الرأسمالية،

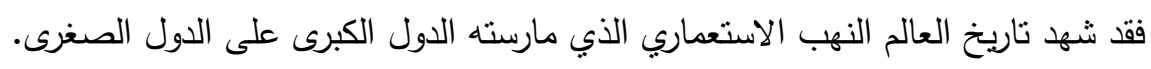

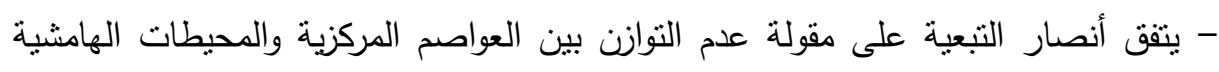

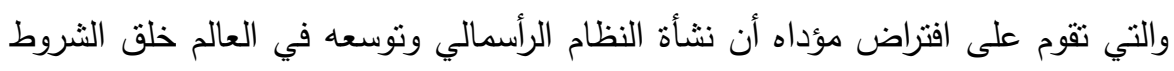

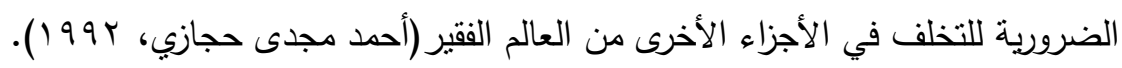

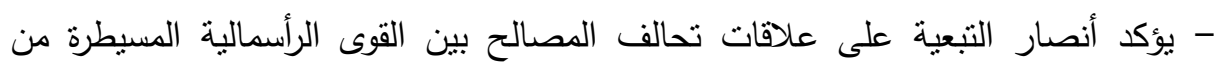

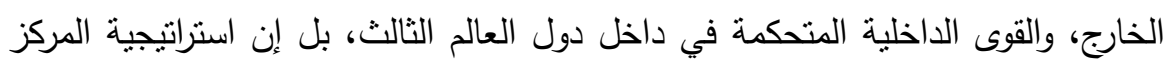

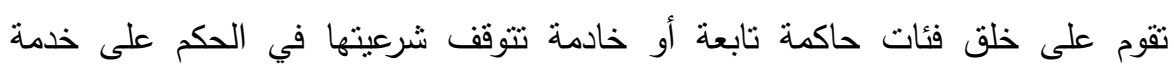
الاقتصاد الأم (العواصم) وتصبح هذه الفئات مدعمة للتبعية وميسرة للتغلغل الرأسمالي تلئي داخل هذه الدول، ومسرعة بالاندماج الكامل في السوق الرأسمالي العالمي.

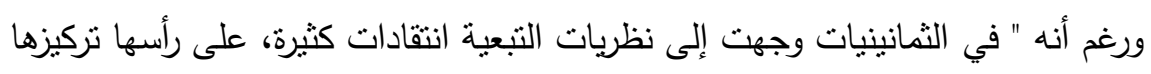

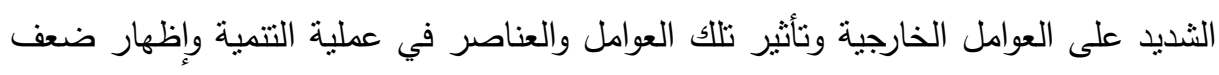
التتمية أو توقفها بسبب تلك العناصر، وإرجاع التخلف إلى تأثثر نتائج انتشار التركيبة الرأسمالية / الليبرالية، وقال النقاد أنه قد يكون العكس هو السبب، أى ضواع ضعف رأس المال وانعدام الليبرالية (سامى خشبة، ج ـ . ب). إلا أنه رغم ذلك، فإن التطورات العالمية التي أفرزت هذه الانتقادات وغيرها، تؤكد نفسها

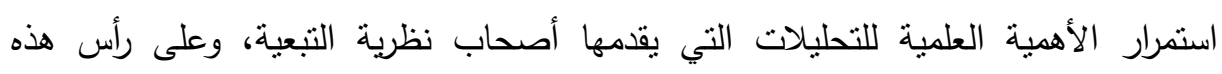

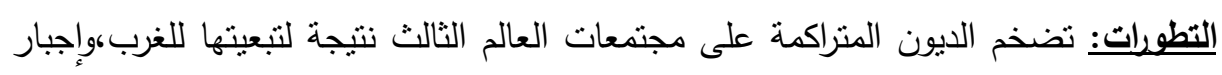

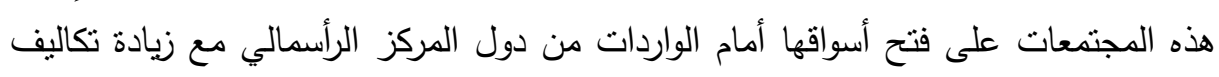
ومطالب الحصول على ما يساعد دول الهامش على نطوير مستوياته العلمية والتكنولوجية،

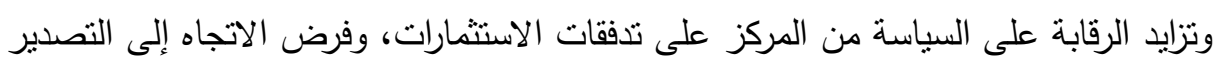

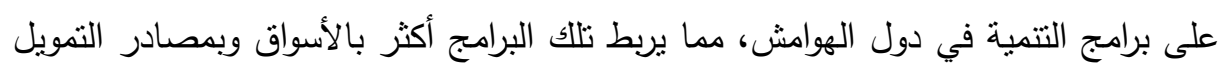

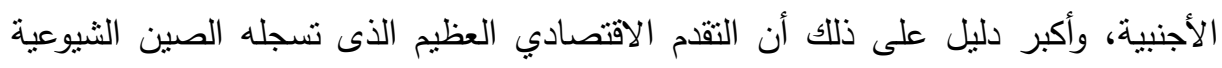

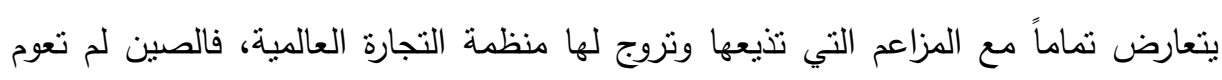

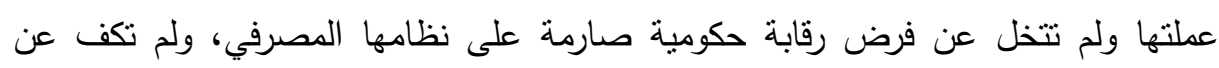

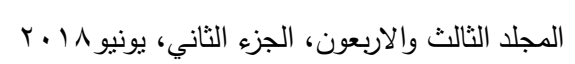


اتخاذ اجراءات تتعارض بنحو صارخ مع الشروط التي يفرضها عادة صندوق النقد الدولي

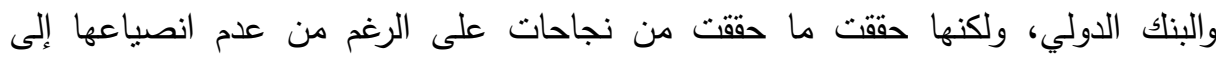
المبادئ التي يريد اتفاق واثنطن إملاءها على الثعوب لا بل، وهذا هو السبب الأهم، لأنها

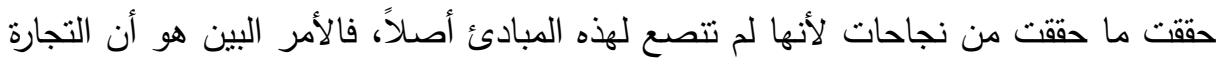

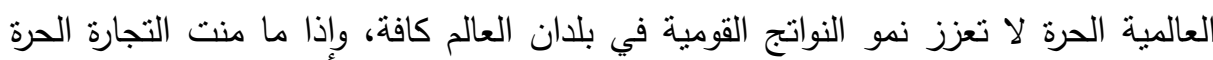

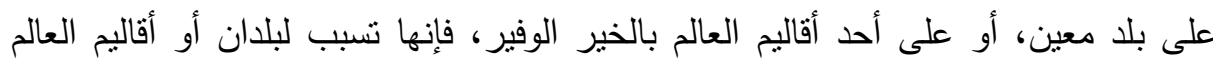

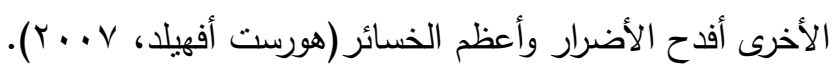

الاتجاه النظري المعتمد للاراسة الحالية: ويعتبر الاتجاه المادي التاريخي من أقرب الاتجاهات

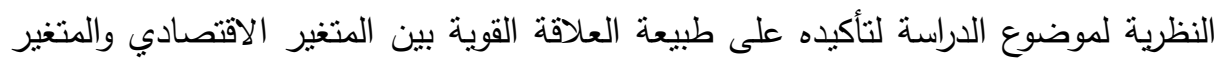
الاجتماعي وما يقدمه من تحليل دقيق لطبيعة التفاعلات وما يفرزه من تغيرات ثورية وجذرية

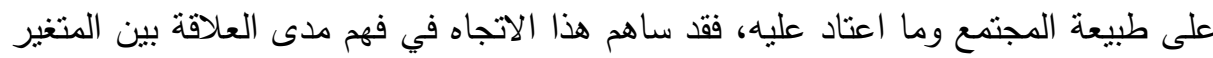

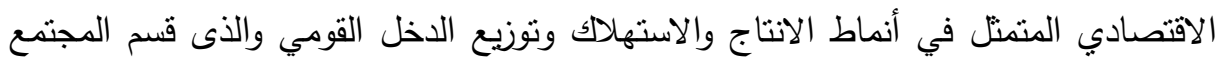
المصري بوجه عام والمجمتع الريفي بوجه خاص إلى مجتمع شديد الفقر وآخر شديد الثراء وحتمية حدوث تغير في أفراد المجتمع والجهات الحكومية للحد من الآثار السلبية.

\section{الإجباءاهت المنهميه للتواسمة}

1- نوع الدراسة: تعتبر هذه الدراسة من الدراسات الوصفية التحليلية، لأنها أنسب أنواع

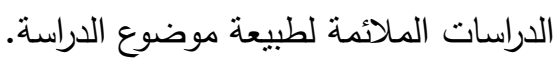
r - منهج الاراسة: المنهج المستخدم في الدراسة هو المنهج الوصفي من خلال استخدام المسح الاجنماعي بالعينة لبعض من الأسر بالقرية مجتمع الدراسة.

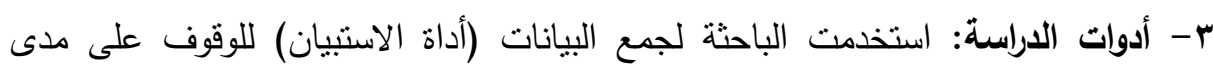
التغير الذي حدث في دور القرية في عملية الانتاج.

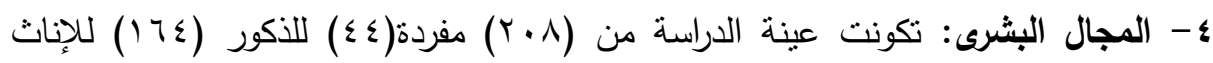
(وذللك لان النساء هن اللاتي تقمن بعمل المنتجات المنزليةواجابات الذكور كانت عما ثقوم بإعداده النساء من هذه المنتجات). 
ه- المجال المكاني: قرية الثيخ ضرغام، التابعة لمركز دمياط، بمحافظة دمياط.

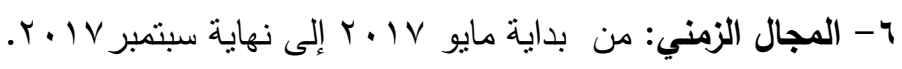
- V شروط العينة: أخذت الباحثة عينة (مقصودة) من الأسر بالقرية وفقا للشروط الآتية:

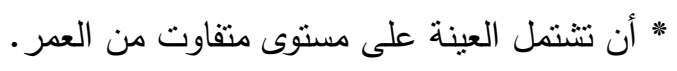
*أن تتنمل العينة على مستوى متفاوت من الدخل. *أن تشتمل العينة على مستوى متفاوت من التعليم.

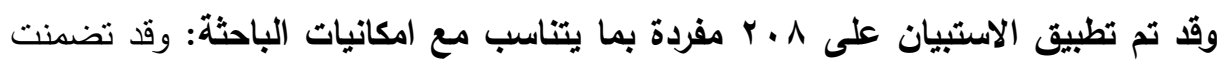

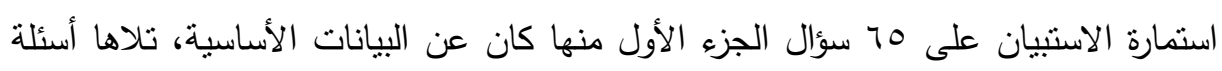

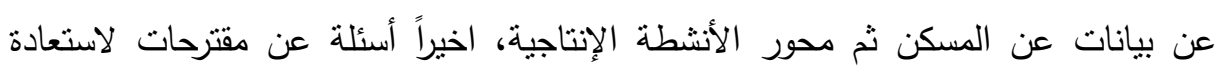
القرية لدورها الإثتاجي مرة أخرى، وتم عمل اختبار الصدق والثبات وكانت نتيجته كالتالي:

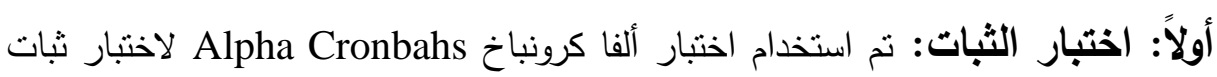
بعدي الدراسة لجميع المتغيرات عدا البيانات الأولية، ويوضح الجدول ( (1) نتائج اختبار الثبات

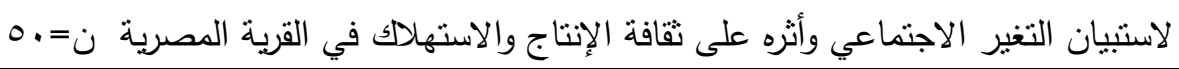

\begin{tabular}{|c|c|c|}
\hline عدد العبارات & معامل آلفا & المتغيرات \\
\hline $0 \leqslant$ & $V Y, \varepsilon$. & اجمالى الاستبيان \\
\hline
\end{tabular}

من الجدول السابق يتضح أن قيمة ألفا لاستبيان التغير الاجتماعي وأثره على نقافة

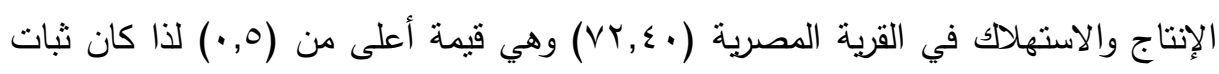

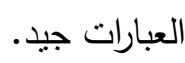

ثاتياً: صدق الاتساق الإخلي: ولمزيد من التحليل قام الباحثون بحساب صدق الاتساق

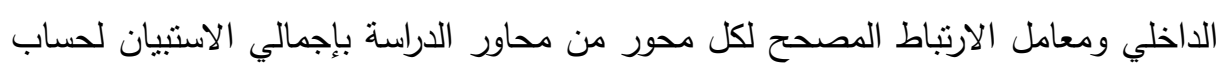

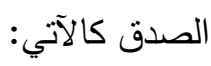
جدول(ץ): صدق الاتساق الداخلي لاستيان التغير الاجتماعي وأثره على نقافة الإنتاج والاستهلاك في القرية المصرية

\begin{tabular}{|c|c|c|}
\hline الاستبيان ككل & \multicolumn{2}{|c|}{ المتغيرات } \\
\hline$\left({ }^{(* * *) \wedge 97, \cdot}\right.$ & معامل ارتباط بيرسون & \\
\hline$\cdot, \cdots 1$ & الدلالة المعنو بة & الي الاسنبيان \\
\hline
\end{tabular}


من الجدول السابق نجد أن الدلالة المعنوية لاستبيان التغير الاجتماعي وأثثر على ثقافة

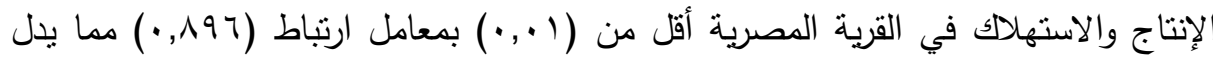
على صدق الاتساق الداخلي للاستبيان.

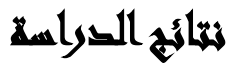

فيما يلي عرض لنتائج الدراسة ومناقشتها والتي تتعلق بعرض لأهم المنتجات التي كانت

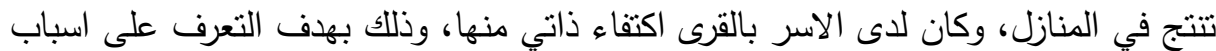

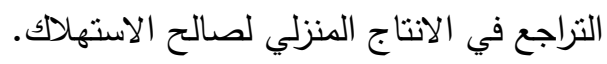

التشاؤل الأول: ما هى أهم التغيرات الاجتماعية التي طرأت على ثقافة الإنتاج والاستهلاك الك

في القرية؟

جدول رقم(؟): يوضح مدى إنتشار الإنتاج المنزلي من الأطعمة والمأكولات ( طعام الإفطار والعشاء ) بوضح مداء)

\begin{tabular}{|c|c|c|c|c|c|c|c|c|c|c|}
\hline \multirow{2}{*}{ المتوسئ المرجح } & \multicolumn{2}{|c|}{ المجموع } & \multicolumn{2}{|c|}{$\bar{y}$} & \multicolumn{2}{|c|}{ آحياناً } & \multicolumn{2}{|c|}{ دائمًا } & \multirow{2}{*}{ الاستجابة } & \multirow[b]{2}{*}{ م } \\
\hline & $\%$ & العدد | العد | & $\%$ & العدد |ل العد & $\%$ & العدد |ل العد & $\%$ & |العدد | & & \\
\hline$\overline{r q, q .}$ & $1 \ldots$ & $\overline{r \cdot \lambda}$ & $r r, V$ & 71 & $0 \leqslant, 1$ & $\sqrt{11 \varepsilon}$ & $1 Y, 0$ & YY & الخبز & 11 \\
\hline$\varepsilon \cdot, \wedge 0$ & $1 \ldots$ & $r \cdot \lambda$ & $r v, 0$ & $\mathrm{VA}$ & $\varepsilon \Gamma, \Gamma$ & 9. & $19, r$ & $\varepsilon$. & الفول المدمس & T \\
\hline rו, & $1 \cdots$ & $r \cdot \lambda$ & $\varepsilon 7, r$ & 97 & $\varepsilon 0, r$ & $9 \leqslant$ & $\Lambda, \vee$ & 11 & الطعدية & $\mu$ \\
\hline or,r. & $1 \ldots$ & $r \cdot \lambda$ & $r Y, 1$ & $\sum 7$ & $\varepsilon q$, & $1 \cdot r$ & $Y \wedge, \wedge$ & 7. & المخلات & $\varepsilon$ \\
\hline$\sum 1, \wedge 0$ & $1 \ldots$ & $r \cdot \lambda$ & $r 7,0$ & $V T$ & $\varepsilon r, r$ & 9. & $r \cdot, Y$ & $\varepsilon Y$ & المربات & 0 \\
\hline$\Sigma 9, \cdots$ & $\ldots$ & $Y \cdot \Lambda$ & ru,o & $V 7$ & $Y \wedge, \Lambda$ & 7. & $r \varepsilon, \tau$ & $V Y$ & البيض & 7 \\
\hline Y0,90 & $\ldots$ & $Y \cdot \Lambda$ & $V \cdot, Y$ & $1 \leq 7$ & $V, V$ & 17 & YY, & $\varepsilon 7$ & اللبن قبل التصنيع & $\mathrm{V}$ \\
\hline$\leqslant \vee, T$. & $1 \ldots$ & $r \cdot \Lambda$ & $r \leq, 7$ & VY & $r 0,7$ & $V \varepsilon$ & $r q, \wedge$ & $7 Y$ & الجبن & $\Lambda$ \\
\hline$\varepsilon \varepsilon, Y_{0}$ & $1 \ldots$ & $r \cdot \lambda$ & $r \varepsilon, 7$ & VY & $\varepsilon r, \Gamma$ & $\wedge \wedge$ & $r r, 1$ & $\varepsilon \wedge$ & السمن & 9 \\
\hline$\Gamma, V$. & $1 \cdots$ & $r \cdot \lambda$ & $0 r, \Lambda$ & $11 \%$ & $Y \wedge, \Lambda$ & 7. & $I V, r$ & 47 & الزبدة & 1. \\
\hline$r \wedge, \cdot 0$ & $1 \cdots$ & $r \cdot \Lambda$ & $\varepsilon 0, Y$ & $9 \varepsilon$ & $r r, v$ & V. & $\bar{Y} 1, r$ & $\varepsilon \varepsilon$ & القتشطة & 11 \\
\hline$r v, \varepsilon 0$ & $1 \cdots$ & $\Gamma \cdot \Lambda$ & $\leqslant 9$, & $1 \cdot T$ & $r 7,9$ & 07 & $r \varepsilon$, & 0. & الزبادي & Tr \\
\hline
\end{tabular}

ا-وصف الجدول: قامت الباحثة بتفريغ الاستبيان، حساب النسب المئوية لكل بند من بنود

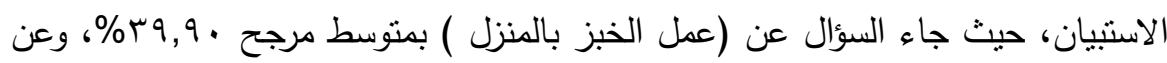

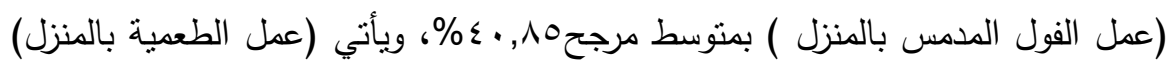




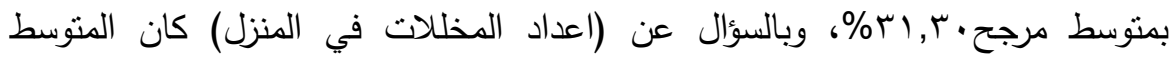

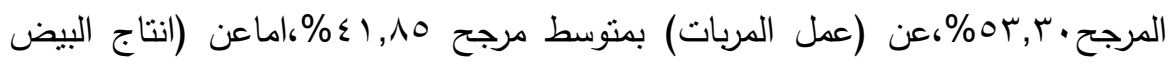

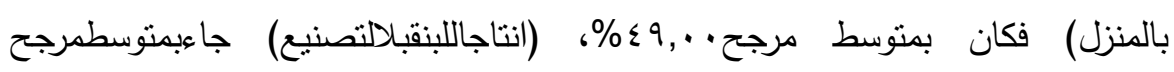

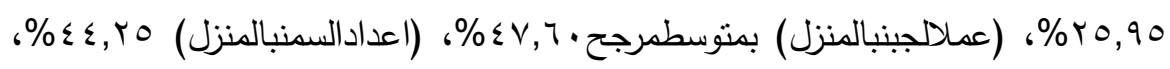

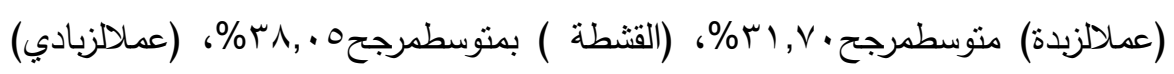

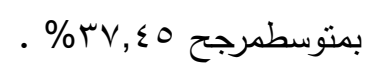
r- تفسير وتحليل الجدول: يتضح من الجدول أن العبارات لا تتعدى نسبة المرجح المئوي

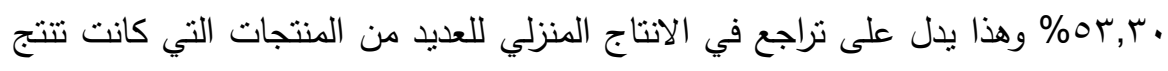
في البيوت من قبل، ويرجع ذلك عدم توفر جانب مهم من جوانب عملية الانتاج الا وهو

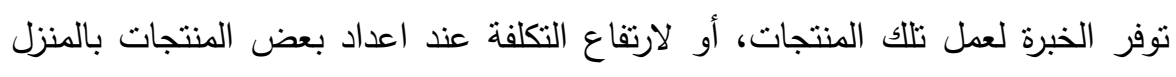

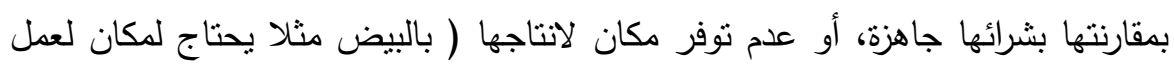
حظيرة بالمسكن وقد لا يتوفر مثل هذا المكان).

\begin{tabular}{|c|c|c|c|c|c|c|c|c|c|c|}
\hline \multirow{2}{*}{ |المتئو المرجح| } & موع ( موع & 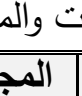 & $y$ & the & \multicolumn{2}{|c|}{ آحيانًا } & \multicolumn{2}{|c|}{ دائمًا } & \multirow[b]{2}{*}{ الاستجابة } & \multirow[b]{2}{*}{ r } \\
\hline & $\%$ & | العدد | & $\%$ & العدد & $\%$ & |العدد & $\%$ & |العدد | & & \\
\hline., .0 & $1 \ldots$ & $r \cdot \Lambda$ & $99, \cdot$ & $r .7$ & $1, \cdot$ & $\bar{T}$ & $\cdot, \cdot$ & . & السجاد & 1 \\
\hline$r, q$. & $1 \cdots$ & $|r \cdot \lambda|$ & $q \Gamma, r$ & $19 \varepsilon$ & 0,1 & 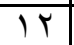 & 1, & $T$ & البلوفرات & $r$ \\
\hline$r, \leqslant 0$ & $1 \ldots$ & $r \cdot \Lambda$ & $97, r$ & r.. & $r, q$ & 7 & 1, & $T$ & الثرابات & $\mu$ \\
\hline $17,{ }^{1} 0$ & $1 \ldots$ & $r \cdot \Lambda$ & $V Y, 1$ & 10 & $r \Psi, 1$ & $\varepsilon \Lambda$ & $\varepsilon, \wedge$ & $1 \cdot$ & المفارش الكروشيه & $\varepsilon$ \\
\hline$\sum 9, \cdots$ & $1 \ldots$ & $r \cdot \Lambda$ & $\mu 7,0$ & $V 7$ & $\Gamma \wedge, \Lambda$ & 7. & $r \varepsilon, 7$ & $V Y$ & تصلبح الملابس & 0 \\
\hline $10, \xi$. & $1 \cdots$ & $r \cdot \Lambda$ & $\vee q, \wedge$ & 177 & 9,7 & Y. & $1 \cdot, 7$ & TY & ملابس البيت & 7 \\
\hline 9,10 & $1 \cdots$ & $r \cdot \Lambda$ & $\Lambda 7,0$ & $1 \wedge$. & $\Lambda, \vee$ & 11 & $\varepsilon, \wedge$ & $1 \cdot$ & ملابس الخروج & $\mathrm{V}$ \\
\hline
\end{tabular}

ا-وصف الجدول: من الجدول السابق يتضح أن العناصر قد تم حساب النسب المئوية لها بالنسبة لجانب انتاج المنسوجات والملابس بالمنزل، فبالسؤال عن (عمل السجاد اليدوي)

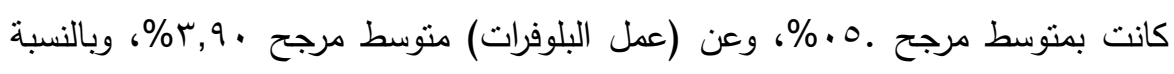

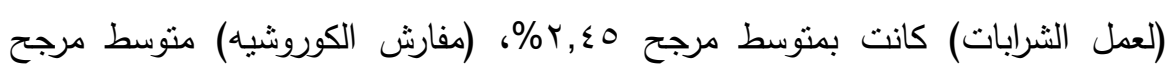

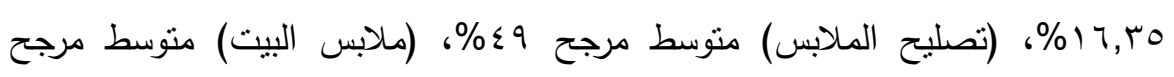

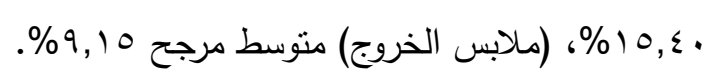


r- تفسير وتحليل الجدول: يوضح الجدول أن العبارات لا تتعدى نسبة المرجح المئوي 9٪\%، وهذا بدل على اتجاه أكثر الاسر إلى الاعتماد على شراء الملابس الجاهزة

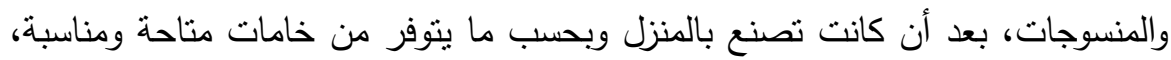

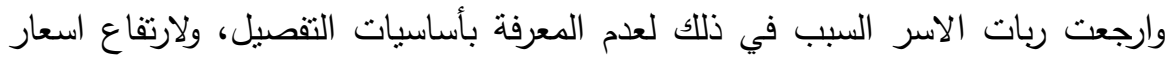
الخامات، ولجودة الملابس الجاهزة مقارنة بما يتم عمله بالمنزل.

التساؤل الثاني: ما هي أهم المتغيرات المؤثرة على ثقافة الانتاج والاستهلاك في القرية؟

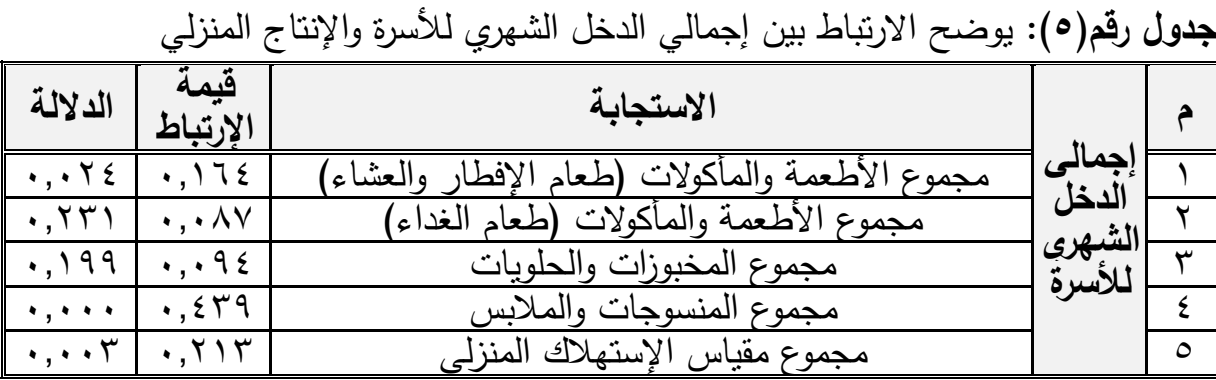
1-وصف الجدول: من الجدول السابق يتضح مدى وجود علاقة بين اجمالي الدخل الثهري

$$
\text { والإنتاج المنزلي للاستجابات التالية: }
$$

من حيث الدخل الثهري للأسرة والإتتاج المنزلي لأطعمة الإفطار والعشاء حيث بلغت

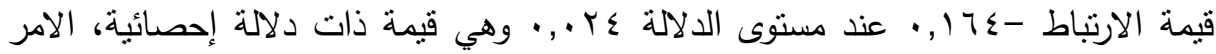
الذي يدل على وجود ارتباط بين الدخل الثهري للأسرة والانتاج المنزلي من اطعة الإفطار والعشاء. بلغت قيمة الارتباط -q جـ,. عند مستوى دلالة ..., وهي قيمة ذات دلالة احصائية، وتدل على وجود ارتباط بين الدخل الثهري والإنتاج المنزلي في الملابس

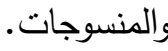

أما عن اجمالي الدخل الشهري ومجموع مقياس الاستهلاك المنزلي بقيمة ارتباط ـ 1 , , عند مستوى دلالة r .,., وهى قيمة ذات دلالة إحصائية، وهي مدلول على وجود الهي 
ارتباط بين اجمالي الدخل الثهري ومجموع الاستهلاك المنزلي ككل لكل من المأكولات بكافة أنواعها والأطعمة التي من المدكن اعدادها بادين بالمنزل.

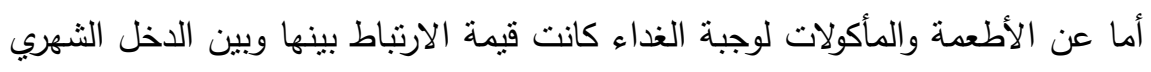

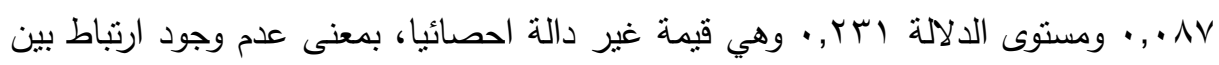

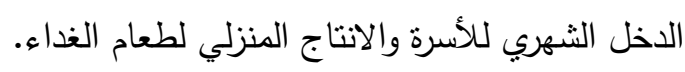

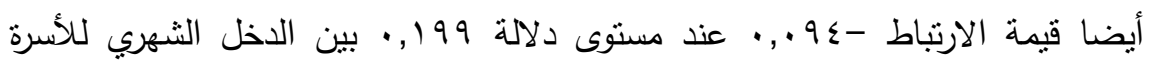

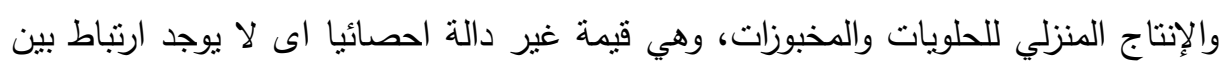
اجمالي الدخل للأسرة والإنتاج المنزلي للمخبوزات والحلويات. r-تفسير وتحليل الجدول: يوضح الجدول أن قيمة ت لحساب العلاقة بين (مستوى الدخل

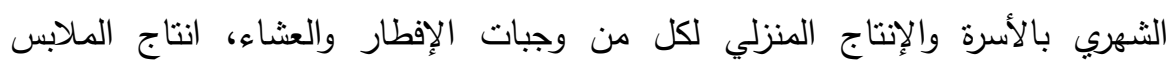
والمنسوجات، ومجموع الاستهلاك المنزلي ) وبين الانتاج المنزلي لكل منهم .

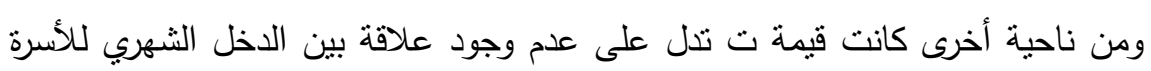

$$
\text { والإنتاج المنزلي لوجبات الغداء واعداد المخبوزات والحلويات. }
$$

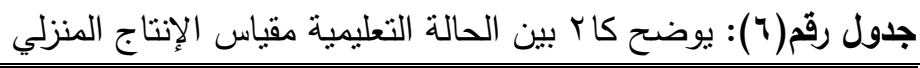

\begin{tabular}{|c|c|c|c|c|c|}
\hline اتجاه الدلالة لصالح & 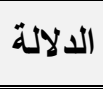 & كأيمة & الاستجابة & & P \\
\hline الأقلّ تعليمًا & $\cdot, \ldots$ & דצז, & 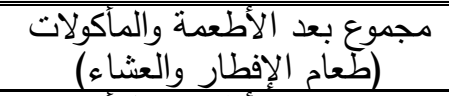 & $\overline{\bar{\lambda}}$ & 1 \\
\hline الأقل تعليمًا & $\cdot, \cdot$ & $90, r 9 \varepsilon$ & $\begin{array}{c}\text { مجموع بعد الأطعدة والمأكولاء الغداء) } \\
\text { (طألغاء }\end{array}$ & 武, & $r$ \\
\hline الآقل تعليمًا & $\cdot, \cdots$, & $1 \leq \vee, \vee \leqslant \Lambda$ & مجموع بعد المخبوزات والحلويات & 7 & $r$ \\
\hline الأقل تعليمًا & $\cdot, \ldots$ & $\mid Y \varepsilon, \varepsilon \leqslant 0$ & مجموع بعد المنسوجات والملابس & & $\varepsilon$ \\
\hline الأقل تعليمًا & $\cdot, \ldots$ & $\varepsilon \wedge \Lambda, \varepsilon \cdot \Gamma$ & مجموع مقياس الإستهلالك الم & & 0 \\
\hline
\end{tabular}

1-وصف الجدول: يتضح من الجدول السابق العلاقة بين الحالة التعليمية ومجموع الأطعمة الإنيا

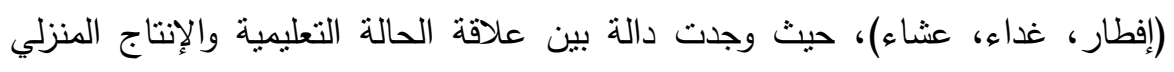

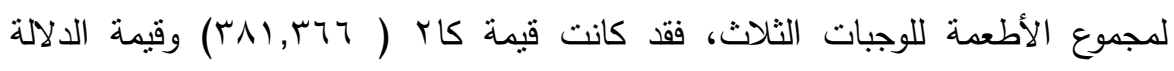

$$
\text { ( · , · ) )، أي انها ذات دلالة إحصائية. }
$$


أيضا توجد علاقة بين الحالة التعليمية ومجموع الأطعمة لوجبة الغداء حيث وجدت دالة

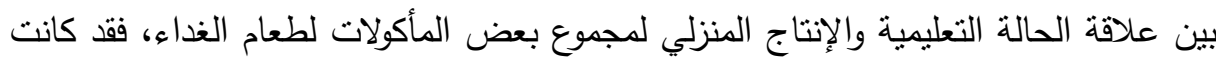

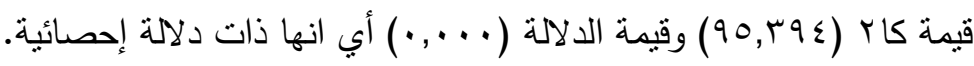

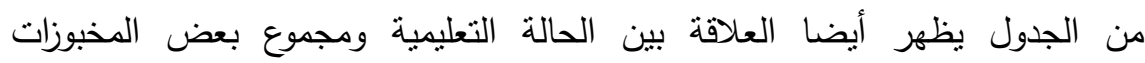

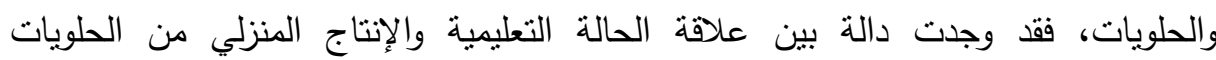

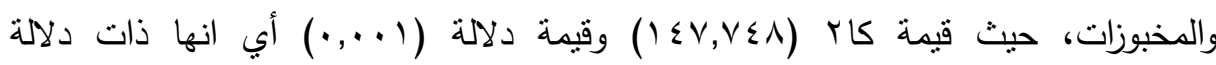
إحصائية.

يظهر الجدول علاقة بين الحالة التعليمبة والإنتاج المنزلي من الملابس والمنسوجات، حيث نوجد علاقة دالة بين الحالة التعليمية والإنتاج المنزلي من الملابس والمنسوجات، فنجد

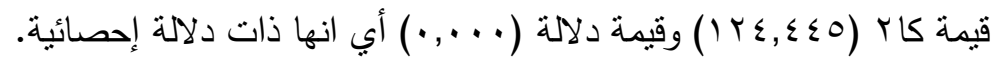

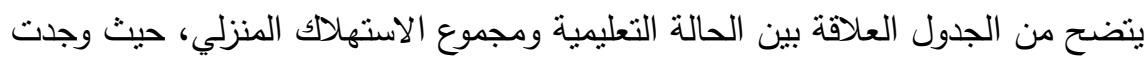

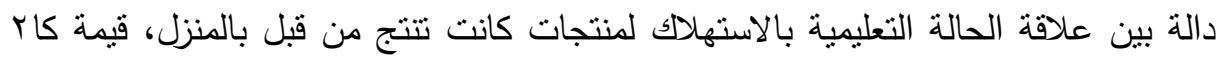

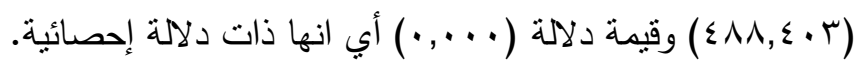
r -تفسير وتحليل الجدول: يتضح من الجدول السابق أن قيمة كاب كانت لصالح الأقل تعليما حيث وجد أن انخفاض المستوى التعليمي عامل مؤثر، وظهر الارتباط بين الحالة التعليمية

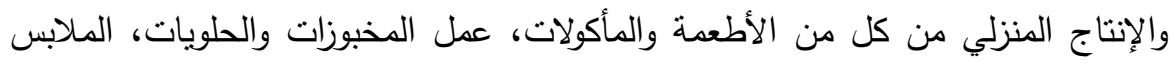
والمنسوجات، حيث أظهرت الدراسة الاعتماد على الاستهلاك الكثر من الإنتاج المنزلي لتلك العناصر السابقة كان من جهة ربات الاسر الأقل تعليما. ومن هنا توصلت الدراسة لعدة نتائج هامة هى:

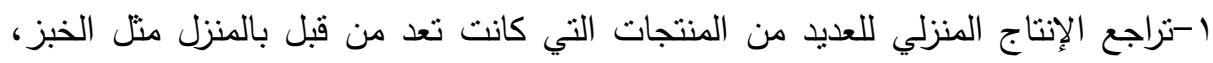

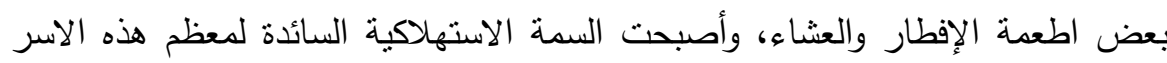
بعد أن كانت وحدة الإنتاج الأولى بالمجتمع.

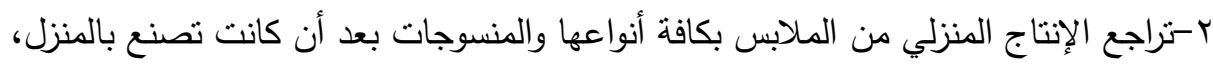
وتأثز اهل القرية بالأسلوب العصري في الملبس، ومجاراة الموضة. 
r- أن هنالك ارتباط بين اجمالي الدخل الثهري للأسرة والإنتاج المنزلي حيث لوحظ ان هناك

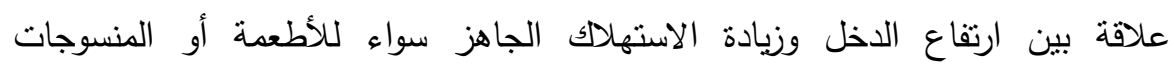

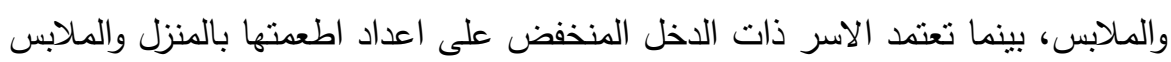

ع -هناك ارتباط بين مستوى التعليم وانخفاض الإنتاج المنزلي جاءت لصالح ربات الاسر الأقل

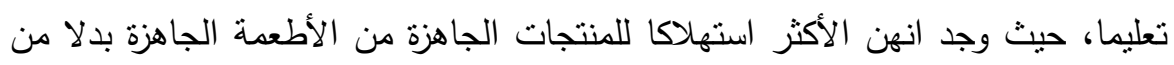

اعدادها بالمنزل، الملابس الجاهزة والمنسوجات، الحلويات الجاهزة بدلا من المنزلية.

\section{تروسيامت التوراسمة}

ا-زيادة الوعى وتتجيع ربات البيوت للاتجاه للإنتاج المنزلي مرة أخرى وتدريب غير الملمات

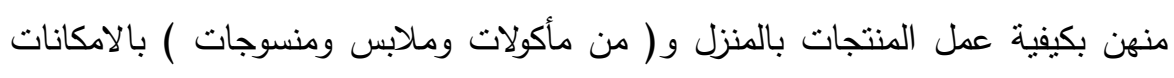

المتاحة.

ب-رشيد الاستهلاك والحد من هدر الموارد ونشر الوعى بين الاسر حتى وان ارتفع دخلها

$$
\text { يجب ترشيد الاستهلاك. }
$$

r-محو أمية ربات الاسر اللاتي لم يمنحن قسط كافي من التعليم، ونتجيع من تقوم منهم

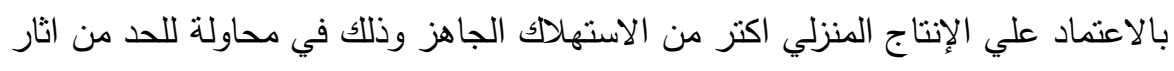

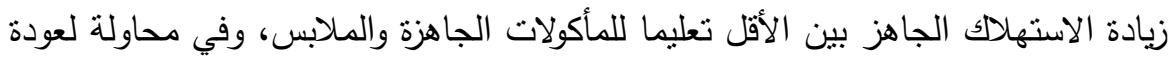
القرية لدورها في عملية الإنتاج مرة أخرى.

\section{المراجــ}

سوزان أحمد أبو رية ( ( . ب): تحديث الصناعة المصرية للتعامل مع متغيرات العصر ، مركز بحوث التتمية التكنولوجية، القاهرة

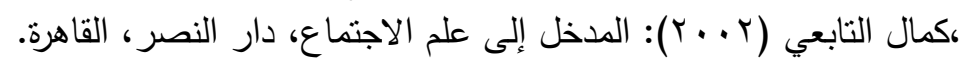

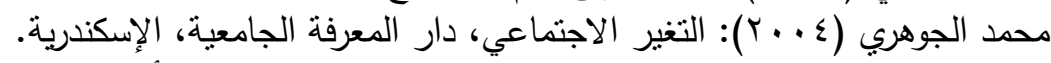

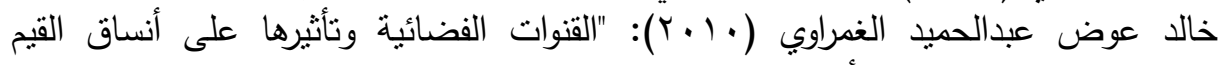

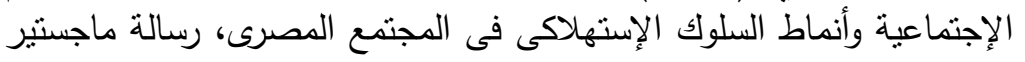

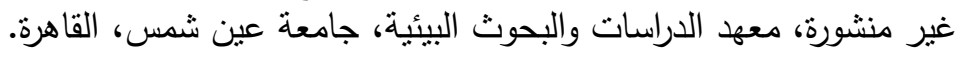

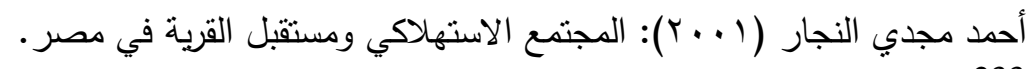

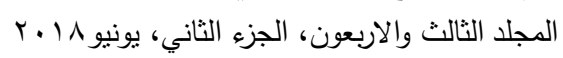




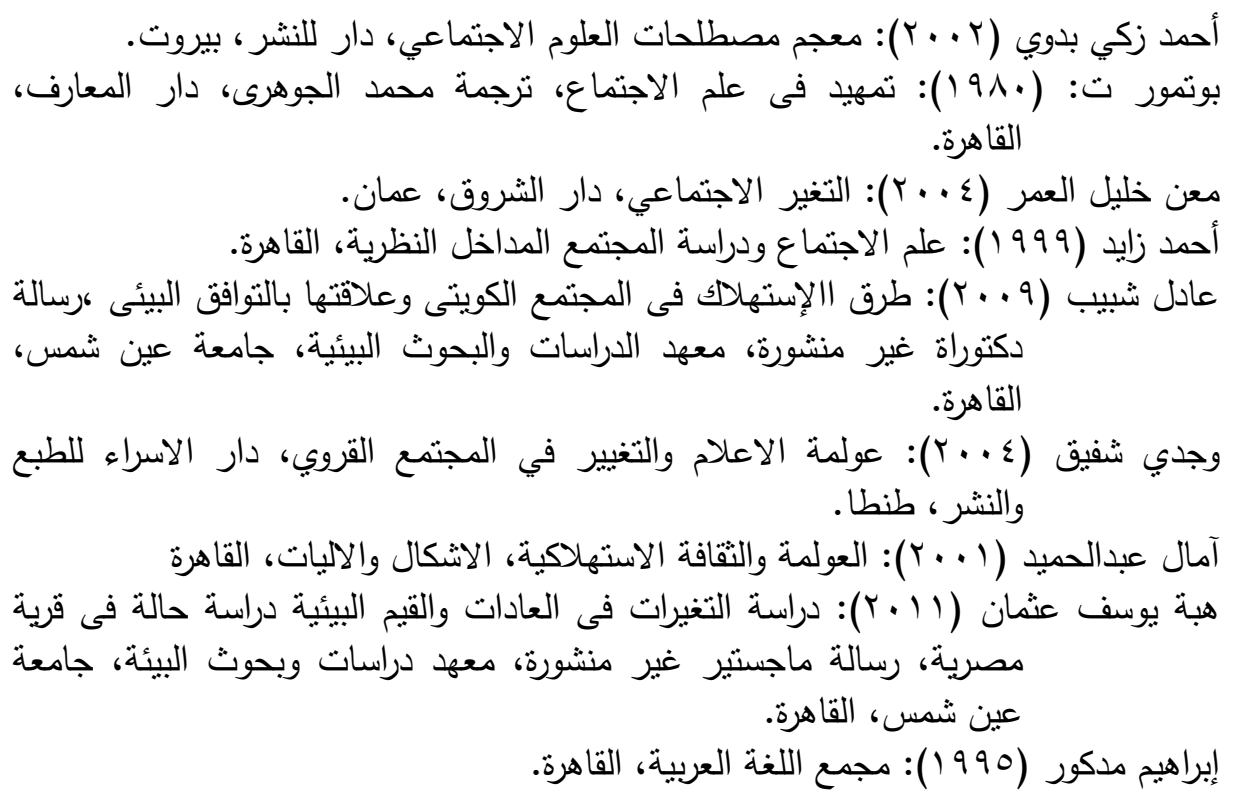

Abdul Razak Kamaruddin , et al, (2009): The World of Consumption: The Material and Cultural Revisited(Economics as Social Theory), Routledge,London, $\mathrm{p}: \mathrm{x}$

Xina, Y , et al .,:Elusive Consumption, Berg Puplishers, New York, U.S.A ,2011,P:1. 


\title{
SOCIAL CHANGE AN AL CHANGE AND ITS IMPACT ON THE CULTURE OF PRODUCTION AND SUMPTION IN THE EGYPTIAN VILLAGE
}

\author{
Nawreg, Dalia, E. ${ }^{(1)}$; Ahmed, H. A. ${ }^{(1)}$ and Morad, A A. ${ }^{(2)}$ \\ 1) Institute of Environmental Research and Studies, Ain Shams \\ University 2) Faculty of Arts, Menofia University
}

\begin{abstract}
The social change is one of the human characteristics in different ages and societies. The social change refers to changes in the social system of the society, which may include the changes in nature, social institutions, social behavior or social relations. some of change aspects we try to monitor through this study is the social change and its impact on the culture of production and consumption in the Egyptian village, i.e. identify the aspects of change emerged in the forms of production and consumption in the village by clarifying variables such as age, social status, income level, educational status, housing status of the respondents, to recognize the most important reasons for the decline in production versus consumption. The study aims to identify the most important changes occurred in the culture of production and consumption in the village. The study focused on housewives as they are the main component in the household production for food and clothing. The study sample consisted of 208 individuals whose educational and social levels differed and their incomes varied. The study relied on the social survey by sample for a group of housewives in the village. In the collection of data, the researcher used the questionnaire tool to determine the extent of the change in household production and consumption for food and clothing as one of the consumption aspects. The study found several findings that showed the decline in production in favor of consumption and the innovation of new forms of consumption.
\end{abstract}

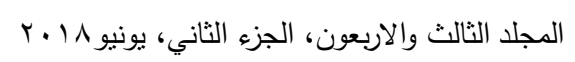

